\title{
Proprietary Income, Entrepreneurial Risk and the Predictability of U.S. Stock Returns
}

\author{
Mathias Hoffmann, University of Dortmund \& CESifo* \\ First version: October 2004. This version: May 31st 2005. \\ Comments Welcome.
}

\begin{abstract}
This paper contributes to a recent empirical and theoretical literature initiated by Heaton and Lucas (JoF 2000) that suggests that proprietors are an important group of stockholders and that entrepreneurial risk could therefore help explain time-varying risk premia on the aggregate stock market. I use the intertemporal budget constraint of the average U.S. household to derive a cointegrating relationship between consumption and income from proprietary and non-proprietary wealth. I call this cointegrating relationship the $c p y$-residual. I interpret cpy as an entrepreneurial risk factor, because it mainly reflects cyclical fluctuations in proprietary income and because it is highly correlated with cross-sectional measures of idiosyncratic entrepreneurial risk. The cpy residual turns out to be a potent predictor of excess returns on the aggregate stock market in postwar U.S. data. However, this predictive power has started to decline since the beginning of the 1980s as stock market participation has widened with the advent of tax-deferable employer-sponsored pension plans and as proprietary income risk has become more easily diversifiable in the wake of state level bank deregulation.
\end{abstract}

${ }^{*}$ This paper is part of the project The International Allocation of Risk funded by Deutsche Forschungsgemeinschaft in the framework of SFB 475. A part of this paper was written while the author was visiting CESifo at the University of Munich. I greatly appreciated the hospitality of CESifo and its staff. Discussions with Sascha Becker, Nils Gootfries, Jim Nason, Michale Moore and Bent Sørensen have contributed substantially to shaping the ideas put forward in this paper. I would also like to thank seminar participants at Humboldt-University Berlin and at Uppsala University for their comments and for helpful discussions. Any errors are mine. E-Mail:m.hoffmann@wiso.uni-dortmund.de Web: http://www.wiso.uni-dortmund.de/ae Postal Address: Dept. of Economics, University of Dortmund, D-44221 Dortmund, Germany. 
KEYWORDS: NON-INSURABLE BACKGROUND RISK, ENTREPRENEURIAL INCOME, EQUITY RISK PREMIUM, LONG-HORIZON PREDICTABILITY.

JEL SUBJECT AREAS: E 21, E31, G12

\section{Introduction}

In 1983 no more than $19 \%$ of all U.S. households owned any publicly tradeable equity. While the share of stockholding households has since grown dramatically, most publicly tradeable equity in the United States is owned by a small fraction of households. As shown by Heaton and Lucas (2000b), these households tend to be relatively wealthy and they also own a lot of private, non-public (proprietary) capital from which they derive much of their income.

These observations single out the proprietors of non-corporate businesses (entrepreneurs) as a group of stock owners that may be particularly interesting from an asset pricing perspective: the risks associated with proprietary, non-corporate entrepreneurial activity are largely non-diversifiable. Noncorporate businesses typically have no direct access to capital markets. While proprietors may still be able to insure their income by smoothing fluctuations in business cash-flow through bank loans, small business access to credit markets is also likely to be limited, due to moral hazard and adverse selection or due to institutional barriers.

At a theoretical level, an increase in non-diversified idiosyncratic risk (also referred to as 'background risk') will tend to lower demand for risky assets. So, if - for whatever reason - stock market particpation is limited so that proprietors own a large share of the stock market, then fluctuations in entrepreneurial background risk could drive expected stock returns. The impact of limited participation on the size of the equity premium has been explicitated in e.g. Vissing-Jorgensen (2002) and Polkovnichenko (2004). The role of non-insurable risk in asset pricing has been formalized in work by Constantinides and Duffie (1996), Heaton and Lucas (1996, 2000a) and Jagannathan and Wang (1996). Heaton and Lucas (2000b) highlight the empirical role of entrepreneurial background risk for stock returns by demonstrating that fluctuations in aggregate proprietary income help explain the cross-section of stock returns.

This paper examines the empirical relevance of this mechanism in explaining stock returns over time. My main result is that, over the postwar period, cyclical fluctuations in proprietary income have been a good predictor of stock returns. I also document that - in accordance with the theoretical mechanism 
- the predictive power of proprietary income for stock markets has declined since the beginning of the 1980s as stock market participation has started to widen with the advent of tax-deferable employer-sponsored pension plans and as proprietary income risk has become more easily diversifiable in the wake of state level bank deregulation. Finally, I show that cyclical fluctuations in aggregate proprietary income are correlated with cross-sectional measures of idiosyncratic entrepreneurial risk. These findings provide strong support for the empirical importance of the entrepreneurial income risk mechanism in explaining post-war U.S. stock market data.

The paper contributes to a growing body of empirical literature that documents that asset prices do not only have important temporary components but that these temporary components are predicted by theoretically founded macroeconomic variables. In particular, my empirical framework builds on the studies by Lettau and Ludvigson $(2001,2004)$ who have shown that an empirical approximation of the consumption wealth ratio, the cay residual, has considerable forecasting power for excess equity returns at short to medium horizons.

While the results obtained by Lettau and Ludvigson are consistent with a wide class of theoretical models, they are silent about a particular theoretical explanation for the predictability of the equity premium. This paper explores empirically to what extent a particular mechanism - idiosyncratic background risk in entrepreneurial income coupled with limited participation in stock markets - can help to explain why the consumption wealth ratio predicts stock market returns.

The empirical analysis in this paper interprets proprietary income as the dividend to non-corporate entrepreneurial wealth. This allows me to obtain an alternative empirical characterization of the consumption-wealth ratio as a cointegrating relationship between various forms of income: consumption $(c)$, proprietary $(p)$ and other forms of income $(y)$.

This cointegrating relationship - to which I refer as the cpy-residual mainly reflects temporary variation in proprietary income and it is highly correlated with the cay-residual, as identified by Lettau and Ludvigson (2001, 2004). Very much as cay, the cpy residual outperforms other standard predictors of (excess) stock returns such as the dividend price ratio and the payout ratio at relatively short horizons. While cpy cannot outperform cay as predictor of excess returns at short to intermediate horizons, it performs considerably better at horizons between 3 and 6 years.

Clearly, proprietary income could be correlated with stock returns for reasons that have nothing to do with the non-insurable background risk mechanism that motivates the analysis here: profits by corporate and non-corporate businesses may comove over the business cycle. As financing conditions vary 
over the business cycle, so could corporate retained earnings (Gertler and Hubbard (1993)). Indeed, my results suggest that proprietary income predicts corporate dividends over the business cycle. But the predictive power of proprietary income for excess returns on stocks by far exceeds what can be explained by time-variation in dividends. Furthermore, proprietary income has only very limited forecasting power for corporate earnings. Finally, the interpretation of cpy as a distress factor capturing idiosyncratic entrepreneurial risk is supported by the fact that it is highly correlated with the cross-sectional variance of state-level proprietary income growth.

The set of findings presented in this paper is consistent with the view that over the sample period examined in this paper, 1952-2002, the proprietary income mechanism has been quantitatively important in explaining asset returns. But my results are also evidence that entrepreneurial income risk cannot be the entire story behind the explanatory power of the consumption-wealth ratio for excess returns, at least not over the entire sample period: first, at relatively short horizons, the consumption-wealth ratio contains valuable information about future stock returns that is not contained in the transitory component of proprietary income as captured by cpy. Secondly, as more households have begun to hold stocks since the beginning of the 1980s and as banking deregulation has facilitated the sharing of proprietary income risk, we should expect the role of the entrepreneurial background risk mechanism to have decreased. While I document that this is indeed the case, there is no evidence that stock returns have become less predictable from the consumption-wealth ratio.

The remainder of this paper is structured as follows: In the next section, I use the intertemporal budget constraint of the household sector to derive a long-term (cointegrating) relationship between consumption and various components of personal income, notably proprietary income. I then proceed to the empirical analysis, identify the cointegrating relationship cpy in the data and show that it mainly captures variation in proprietary income. I then use the cointegrating error to forecast stock market returns, comparing the outcome to the forecast performance of cay, the temporary component of the consumption wealth ratio. In section five, I demonstrate that the correlation between cpy and aggregate stock markets has decreased due to widened stock market participation and better access of small firms to credit. A final section discusses the results and concludes. 


\section{Entrepreneurial income and the consumption- wealth ratio}

The analysis in this paper uses fifty years of aggregate time series data to construct an entrepreneurial risk or 'distress' factor by extending the approach suggested by Lettau and Ludvigson $(2001,2004)$ and Campbell and Mankiw (1989). This approach has the advantage that it rests on minimal theoretical identifying assumptions since it is based solely on the log-linearization of the average household's intertemporal budget constraint. The log-linearization allows me to derive a cointegrating relationship between the logaritms of consumption $(c)$, proprietary $(p)$ and other forms of income $(y)$. My interpretation of this cointegrating relationship as an entrepreneurial risk factor rests on the insight that if proprietary income is low in relation to other incomes in the economy and in relation to aggregate consumption, then times for the average entrepreneur are likely to be hard and entrepreneurial risk will be high. Conversely, levels of proprietary income above the long-run trends in income and consumption will reflect periods of low entrepeneurial risk. I discuss and empirically underpin this interpretation in detail below. Before, I turn to deriving the cointegrating relationship from the budget constraint of the average household.

\subsection{A long-run relation between consumption and the dividends from wealth}

For the purposes of this paper, I find it useful to state the budget constraint of the average household in present-value form: I write total wealth, $\Psi_{t}$, as the sum of proprietary wealth $\Pi_{t}$ and other forms of wealth $\Theta_{t}$ :

$$
\Psi_{t}=\Pi_{t}+\Theta_{t}
$$

where total wealth $\Psi_{t}$ is the present value of all current and future consumption expenditure and the right hand side gives the present value of all incomes, partitioned according to whether this income is derived from proprietary entrepreneurial or non-proprietary activity (wages and salaries, dividends). Letting lower case letters denote logarithms, this identity can be rewritten as

$$
\log \left(1-\frac{\Pi_{t}}{\Psi_{t}}\right)=\theta_{t}-\psi_{t}
$$

The share of proprietary wealth in total wealth is $\Pi_{t} / \Psi_{t}=\exp \left(\pi_{t}-\psi_{t}\right)$ and I denote the long-run mean of $\Pi_{t} / \Psi_{t}$ with $\gamma$. Hence, I can write $\gamma=$ 
$\exp (\overline{\pi-\psi})$, where $\overline{\pi-\psi}$ is the long-run mean of the logarithm of $\Pi_{t} / \Psi_{t}$. I now expand the left hand-side of (2) around $\overline{\pi-\psi}$ to obtain.

$$
\log \left(1-\frac{\Pi_{t}}{\Psi_{t}}\right) \approx \kappa-\frac{\gamma}{1-\gamma}\left[\pi_{t}-\psi_{t}\right]
$$

where $\kappa=\log (1-\gamma)-\gamma(\overline{\pi-\psi})(1-\gamma)^{-1}$ is a constant. Plugging this back into (2) and rearranging yields

$$
\psi_{t}-\gamma \pi_{t}-(1-\gamma) \theta_{t}=-(1-\gamma) \kappa
$$

This equation is the basis for the long-run relationship between consumption and proprietary income that I am going to consider in this paper. The logarithms of total, proprietary and non-proprietary wealth are not directly observable. But the long-run relation between wealth and its sub-components can be made observable by acknowledging that proprietary income is the dividend to proprietary wealth as any other form of income must be the dividend of other (non-proprietary) forms of wealth. Ultimately, consumption is the dividend on total wealth. The gist of my argument is that consumption, proprietary income and labour income are all individually integrated of order one $(I(1))$, but all three variables differ from their respective permanent values (i.e. from the respective wealth components) only by an $I(0)$-process. Hence, replacing $\psi, \pi$, and $\theta$ in (3) with consumption $(c)$, proprietary $(p)$ and non-proprietary income $(y)$ respectively, one must obtain an $I(0)$ process, so that

$$
c p y_{t}=c_{t}-\gamma p_{t}-(1-\gamma) y_{t}
$$

defines a cointegrating relationship. This cointegrating relationship is more formally derived in the appendix. In analogy to Lettau and Ludvigson, I refer to it via the acronym 'cpy'. An immediate empirical implication of (4) is that the coefficients of the cointegrating vector should correspond the long-run shares of proprietary and other wealth in total wealth.

By Granger's representation theorem, the fact that $c, p$ and $y$ cointegrate also implies that their joint dynamics is captured by a vector error-correction mechanism. Stacking the three variables so that $\Delta \mathbf{x}_{t}=\left[\begin{array}{ccc}\Delta c_{t} & \Delta p_{t} & \Delta y_{t}\end{array}\right]^{\prime}$ one can then write the vector error-correction model (VECM) as

$$
\Gamma(\mathbf{L}) \Delta \mathbf{x}_{t}=\boldsymbol{\alpha} \boldsymbol{\beta}^{\prime} \mathbf{x}_{t-1}+\varepsilon_{t}
$$

where $\boldsymbol{\beta}^{\prime}=\left[\begin{array}{lll}1 & -\gamma & 1-\gamma\end{array}\right]$ is the cointegrating vector, $\boldsymbol{\alpha}$ is a vector of adjustment loadings, $\boldsymbol{\Gamma}(\mathbf{L})$ is a $3 \times 3$ matrix polynomial in the lag operator and $\varepsilon_{t}$ is a vector of disturbance terms. The error-correction mechanism implies 
that at least one of the three variables consumption, labour and proprietary income have to adjust to restore cpy to its long-run mean. Hence, changes in at least one of the three variables will have to be predictable, i.e. at least one of the variables will have a statistically significant transitory component. I provide ample evidence that cpy can indeed be associated with the temporary component of proprietary income.

\subsection{Interpreting $c p y$ as a proxy of (idiosyncratic) en- trepreneurial income risk}

The theoretical mechanism that I wish to investigate rests on the presence of non-diversified idiosyncratic risk at the household level. While household level data is available from various sources, the sample period covered by these data sets at best reaches back to the early 1980s and the data is at an annual frequency. To contribute to the recent literature on the predictability of stock returns, it is clearly desirable to use long stretches of quarterly data, though. Furthermore - and the results of this paper underscore this point - the roles of non-diversified entrepreneurial income risk in explaining asset returns may have been more important in the more distant past than more recently, because financial innovation has allowed more (non-entrepreneur) households to participate in stock markets and may - at the same time - have given more entrepreneurs the possibility to lay off a part of their previously non-diversifiable risk. Household level data for the 1950s and 1960s are, however, not available.

Instead, I suggest to interpret cpy as a distress factor for the owners of non-incorporated businesses. I will base this interpretation on two empirical findings: first, I show that mean reversion in cpy is mainly driven by proprietary income. Hence, cpy identifies the temporary deviation of of proprietary income from its long-run relation with aggregate consumption and labour income. My argument is that if proprietary income is low in relation to aggregate consumption and other (i.e. non-proprietary) income, then idiosyncratic risk for the average proprietor is high: when times are hard for the average small business, then the average proprietor faces a relatively high probability of having to liquidate private assets, e.g. in order to provide cash flow for the business. Proprietors will be afraid of having to liquidate public equity holdings when prices are low. Therefore, to hold the outstanding stock willingly, they will have to be compensated with high expected returns.

The the second empirical finding that underpins the interpretation of cpy as an entrepreneurial risk factor is that cpy is highly correlated with the crosssectional standard deviation of the idiosyncratic component of proprietary 
income growth at the state level. This suggests that cpy captures not only the risk of the average proprietor relative to the average non-proprietor but that it is also a good proxy of the idiosyncratic risk faced by each proprietor relative to other proprietors.

\section{Empirical implementation}

\subsection{Data}

The data are quarterly data on personal income and its components from the U.S. Bureau of Economic Analysis. Consumption data is from the same source. The data range is from 1952Q1 to 2002Q2.

An important issues in the preparation of the data used for analysis is the choice of consumption data. Since durables are consumed over several periods total consumption is therefore likely to be a lot more variable than the true consumption stream (relevant for utility maximization) that should only include non-durables consumption and the stream of consumption services from the stock of durables. Lettau and Ludvigson follow a convention in the literature that measures consumption by expenditure on non-durables excluding shoes and clothing and on services. This convention is justified under the assumption that true logarithmic consumption is a constant multiple of the logarithm of non-durables consumption.

However, as argued by Rudd and Whelan (2002), total consumption expenditure should be used under the present empirical approach since what matters for the intertemporal budget constraint is not the stream of consumption services but just total expenditure on consumption: the present value of total consumption has to be equated to the present value of the dividends of wealth.

I address this problem by using both total and non-durables and services consumption (excluding shoes and clothing) in my empirical implementation. The results of the exercise will be discussed in the next section.

The right hand side of the budget constraint should reflect the present value of private disposable income. While data on disposable income are available, we only have data on gross income components such as proprietary income. I therefore have to make assumptions about how taxes are distributed across the various kinds of income. The most obvious is to assume that all sources of income have the same average tax rate. I use this assumption here, so that disposable proprietary income is just total (gross) proprietary income minus total taxes times the share of gross proprietary income in total gross income. 
Finally, I deflate all variables with the CPI for total consumption.

\subsection{Cointegration analysis}

To identify the number of cointegrating vectors, I used Johansen's test procedures, the maximum eigenvalue and the trace test statistics. The results, provided in table (1), clearly indicate the presence of one cointegrating relationship, irrespective of whether non-durables or total consumption is used.

I proceeded to estimate the cointegrating vector in two ways: first, based on Johansen's (1988) full information maximum likelihood approach and second based on a cointegrating regression in the spirit of Engle and Granger (1987). Again, the exercise is performed for both total consumption and for non-durable consumption.

Shocks to income and consumption are likely to be correlated. While the full-information approach takes care of this problem, in the cointegrating regression I account for it by applying Stock and Watson's (1993) dynamic OLS procedure which amounts to adding leads and lags of first differences of the regressors. Specifically, I estimate the following cointegrating relation:

$$
c_{t}-\beta_{p} p_{t}-\beta_{y} y_{t}
$$

Table 2 reports the estimated cointegrating vectors obtained from the different consumption data sets and based on both the full information and the regression based method. The estimate of the cointegrating vector does not depend on the choice of estimation method. It does, however, depend on the choice of consumption data. While the coefficient on proprietary income is around 0.25 and around 0.75 on other income when total consumption is used, both coefficients increase slightly when non-durables consumption is employed in the estimation. What can explain this difference?

Note first that the sum of the coefficients when total consumption is used is exactly unity: this suggests that the net present value of proprietary income accounts for 25 percent of total discounted incomes, other income for the remaining three quarters. I will shortly discuss the plausibility of these numbers further. But note first that the sum of coefficients increases by 8 percent if only non-durable consumption is used in estimation and this increase falls almost equally on both coefficients. One interpretation of this is that the present value of durables consumption accounts for 8 percent of the present value of total consumption. To gauge the plausibility of this number, I examine what share of household net worth can be ascribed to the stock of durable consumption goods. Data on the replacement value of 
durables are contained in the household net worth data base from the Federal Reserve Board of Governors. Inspecting these data reveals that over the post-war period, the stock of consumer durables accounted for between 6-8 percent of household net worth. Hence, in the long-run the sum of proprietary and non-proprietary wealth should exceed the present value of non-durable consumption by roughly 6-8 percent, consistent with the results reported in table 2.

The estimated cointegrating vectors suggest that the present value of proprietary income amounts to about a quarter of the total present value of consumption. Lettau and Ludvigson (2001) find that household financial wealth - i.e. the present value of all household cash flow derived from capital - accounts for roughly one third of total wealth in their cay relationship, in line with standard estimates that put the capital share for the U.S. economy at a very similar value. According to the National Income and Product Account (NIPA) Tables available from the Bureau of Economic Analysis, proprietary income has accounted for only between one third and one half of all profits in the economy over the postwar period. But over the same period, generally only around one third of all corporate profits have been disbursed as dividends. Since only disbursed dividends become a component of household cash flow (i.e. personal income), this suggests that proprietary income could well account for around three quarters of all household cash flow derived from capital in present value terms. Hence an estimate for $\gamma$ of around $0.25=(3 / 4 \times 1 / 3)$ is consistent both with the evidence from U.S. national accounting data and the findings by Lettau and Ludvigson.

The budget constraint (1) will hold irrespective of any particular economic theory. This, in particular, implies that it should hold for total consumption and the results just reported support this . But the theoretically correct concept of consumption that should enter utility is unobservable since it comprises the consumption services derived from the stock of durables. This service stream will be a lot smoother than durables expenditure itself. It is therefore a standard convention to proxy the theoretical consumption stream by expenditure on non-durables and services alone. This is also the approach adopted in Lettau and Ludvigson and I follow it here. In the sequel of the paper, I will therefore only report results obtained with non-durables consumption data. Specifically, in analogy to Lettau and Ludvigson, I refer to the cointegrating residual via an acronym, as 'cpy' so that

$$
c p y=c_{t}-0.27 p_{t}-0.81 y_{t}
$$


denotes temporary departures of consumption, proprietary and other income from their common trends.

The main proposition I wish to make in this paper is that cpy can be viewed as an indication of fluctuations in entrepreneurial risk. This proposition will be based on a set of empirical findings that that I will document in turn: first, cpy is largely driven by fluctuations in $p$ so that I can interpret cpy as the deviation of $p$ from its trend: if proprietary income is low in relation to aggregate consumption and to other forms of income, then the average proprietor is in relative distress. Secondly, low values of proprietary income (high values of cpy) are associated with a high cross-sectional variance of entrepreneurial income. Third, cpy is correlated with the aggregate consumption wealth ratio and this is the case mainly because, fourth, cpy predicts stocks markets.

I address the first and last of these issues in the next subsections. Evidence on the correlation of $c p y$ with the consumption wealth ratio and with the cross-sectional variance of state-level income can be obtained from figures (1) and (2). Figure (1) plots the cay residual from Lettau-Ludvigson along with the cpy residual estimated here. It is well known from the results in Lettau and Ludvigson $(2001,2004)$ that virtually all temporary variation in cay reflects fluctuations in the stock of financial wealth. Indeed the two residuals share some of the major swings, but they are clearly not the same time series. Their correlation across the sample period is only 0.47 . The comovement, however, seems a lot stronger in the earlier part of the sample. Over 1952 to 1998, i.e.excluding the technology bubble, the correlation is 0.67. And including observations until 1980 only, the two time series appear particularly highly correlated with a coefficient of around 0.8. Indeed, the early 1980s seem to mark a break in the correlation between cpy and cay that also highlights an important conceptual difference between the two residuals: both cpy and cay are obtained from the log-linearization of what is ultimately the same intertemporal budget constraint. But the empirical approximation of the consumption-wealth ratio is based on different variables. Whereas cay contains asset wealth, $a$, and is therefore a function of current asset prices, asset price realizations do not feature in the computation of cpy. The striking correlation between cpy and cay in the first half of the sample period and the subsequent decrease of this correlation would seem to suggest an important change in the link between proprietary income, captured by cpy and the transitory component of stock markets, as captured by cay. I explore the changing structure of this link in more detail below.

Figure (2) plots cpy together with a measure of idiosyncratic entrepreneurial risk. To construct this measure, I used quarterly state-level per capita proprietary income from the Bureau of Economic Analysis from 1969Q1 to 
2001Q4. No earlier quarterly state-level data on proprietary income is available. To capture risk at the business cycle- frequency, I considered growth rates over two-year horizons (growth rates over longer or shorter horizons give very similar results). I then form the idiosyncratic component of this growth rate for each state by deducting the growth rate of U.S.-wide per capita proprietary income. The measure plotted in figure (2) is the cross-sectional standard deviation of these state-specific growth rates for each period.

Visual inspection suggests an important link between these two time series. The correlation coefficient is 0.41 and the $t$-statistics of the regression of cpy on the cross-sectional standard deviation is higher than 4 . This suggests that cpy captures an important element of the cross-sectional heterogeneity in the economic situation of proprietor-run businesses in the United States.

\section{3 cpy as the transitory component of proprietary in- come}

The cointegrating relation between consumption and proprietary and other income allows to identify permanent and transitory components of these variables without further identifying restrictions. To describe the joint dynamics of proprietary income, other income and consumption, I now estimate a cointegrated VAR (VECM) in which I impose the cointegrating vector estimated before. I include one lagged difference of $\mathbf{x}_{t}$ in each equation, as suggested by standard information criteria. The results, reported in table (3), are, however, not very sensitive to the number of lags chosen.

A first impression of the role of transitory components in explaining consumption, proprietary and other income can be gleaned from the coefficient on the lagged cointegrating residual: if this coefficient is zero, the respective variable does not contribute to the error-correction mechanism, implying that it does not contribute to the predictable dynamics that forms the transitory component of the system.

Inspection of the VECM coefficients reveals that only the adjustment coefficient on proprietary income is significant, suggesting that the transitory dynamics in consumption and income is largely due to deviations of proprietary income from its long-run trend. I further examine this proposition by identifying the permanent and transitory components of $c, p$ and $y$ more formally.

I do this in two ways. First, I build on a recent literature inspired by Gonzalo and Granger (1995), Johansen (1997) and Proietti (1997) in which the permanent and transitory components of a cointegrated system are expressed as the linear combination of current levels. In this way, time 
series for the trend and cycles of $c, p$ and $y$ are easily obtained. Specifically, Proietti proposes the following decomposition:

$$
\begin{aligned}
\mathbf{x}_{t} & =\mathbf{C}(\mathbf{1}) \boldsymbol{\Gamma}(\mathbf{1}) \mathbf{x}_{t}+[\mathbf{I}-\mathbf{C}(\mathbf{1}) \boldsymbol{\Gamma}(\mathbf{1})] \mathbf{x}_{t} \\
& =\mathbf{x}_{t}^{P}+\mathbf{x}_{t}^{T}
\end{aligned}
$$

where $\mathbf{C}(\mathbf{1})$ is the long-run response of $\mathbf{x}_{t}$ to shocks, i.e. the loading associated with the random walk component in the Beveridge-Nelson-Stock Watson decomposition of $\mathbf{x}_{t}$.

An alternative approach that allows to obtain variance decompositions and to conduct impulse response analysis.is to identify permanent and transitory shocks directly. A natural way to do this is to acknowledge that $\mathbf{C}(\mathbf{1})$ can be factored as $\mathbf{C}(\mathbf{1})=\mathbf{A} \boldsymbol{\alpha}_{\perp}^{\prime}$ so that

$$
\boldsymbol{\pi}_{t}=\boldsymbol{\alpha}_{\perp}^{\prime} \varepsilon_{t}
$$

can be interpreted as the vector of permanent shocks, the innovations to the random walk component of $\mathbf{x}_{t}$. By construction, shocks that are transitory with respect to all components of the vector $\mathbf{x}_{t}$ must be orthogonal to $\boldsymbol{\pi}_{t}$ so that these shocks must be given by

$$
\boldsymbol{\tau}_{t}=\boldsymbol{\alpha}^{\prime} \boldsymbol{\Omega}^{-1} \varepsilon_{t}
$$

Collecting permanent and transitory shocks into one vector $\boldsymbol{\theta}_{t}$,

$$
\boldsymbol{\theta}_{t}=\left[\begin{array}{c}
\boldsymbol{\pi}_{t} \\
\boldsymbol{\tau}_{t}
\end{array}\right]=\left[\begin{array}{c}
\boldsymbol{\alpha}_{\perp}^{\prime} \\
\boldsymbol{\alpha}^{\prime} \boldsymbol{\Omega}^{-1}
\end{array}\right] \varepsilon_{t}=\mathbf{P} \varepsilon_{t}
$$

From the estimated VECM, it is possible to obtain the Wold-representation

$$
\Delta \mathbf{x}_{t}=\mathbf{C}(\mathbf{L}) \varepsilon_{t}
$$

so that with

$$
\varepsilon_{t}=\mathbf{P}^{-1} \boldsymbol{\theta}_{t}
$$

it is straightforward to identify the variance contribution of permanent and transitory shocks as well as impulse responses.

Figure (3) plots the trend component of consumption, other income and proprietary income along with the variables themselves. As is apparent, again, proprietary income is the one variable in the system with a sizeable transitory component, whereas other components of income as well as consumption are always much closer to their random walk components. This 
message also transpires from the variance decompositions in table (4). ${ }^{1}$ This result is very much in line with the findings obtained by Cochrane (1994) as well as Lettau and Ludvigson (2004): both studies find consumption to be close to a random walk. Lettau and Ludvigson also demonstrate that labour income display almost random-walk behaviour, whereas Cochrane finds that the consumption -income (as measured by GNP) ratio predicts changes in income. The results here identify proprietary income as an important source of this predictability.

Note that our measure of other income, besides labour income, also includes income from assets such as interest payments and - in particular corporate dividends. Cochrane (1994), Campbell (1991) and others have found that dividend growth is hardly predictable, and my result that the sum of labour income and dividends is hardly predictable seems to line up with these findings. Very recently, however, Lettau and Ludvigson (2003, forthcoming) have argued that the consumption wealth ratio does predict dividend growth. The next section reports long-horizon regressions that also show that cpy predicts dividend growth. It would therefore seem surprising that the predictability of dividend growth does not materialize in temporary variation of the 'other income' aggregate. I discuss this issue below, but it should be noted that the facts reported here just imply that the adjustment coefficient on cpy in the 'other income'-equation of the VECM is zero. Hence, other forms of income - and in particular dividends - do not enter the errorcorrection mechanism between consumption, personal income in U.S. data. The findings to be reported below are consistent with this interpretation, even though I also find dividends to be predictable.

The results here may also raise the question why proprietary income is the main predictable component of personal income in U.S. data. A potential explanation may be that proprietary income is the least smoothed of all components of personal income: labour income may be insured through migration, through labour hoarding over the cycle or through unemployment benefit systems. Also, there is evidence that corporations smooth dividend payments, (Cochrane (1994), Lamont (1998)) implying a similar kind of smoothing for income derived from financial assets. Proprietary income, however, is a residual that acts as a buffer for income fluctuations over the business cycle and as such it also has the biggest cyclical component. This interpretation underscores the interpretation of cpy as a distress factor. It is also in line with the finding by Agronin (2004) who reports that the degree

\footnotetext{
${ }^{1}$ Note that the relative variance contributions of permanent and transitory shocks do not require any further identification of the permanent or transitory among themselves. This will only be necessary once we are interested in conducting impulse response analysis. See e.g. Hoffmann (2001)
} 
of aggregate risk sharing over the business cycle is highly correlated with cyclical fluctuations in the share of proprietary income in GDP.

The findings reported here suggest that consumption-income and the consumption wealth ratio are highly positively correlated and - read together with those in Lettau and Ludvigson $(2001,2004)$ - they imply that transitory movements in asset prices are positively associated with transitory fluctuations in proprietary income. One may therefore expect cpy to be a good predictor for asset returns. I turn to a discussion of the forecasting power of cpy for stock market returns in the next section.

\section{$4 \quad$ Predicting stock market returns}

The previous section has established that temporary fluctuations in the cpyrelation largely reflect temporary fluctuations in proprietary income. To the extent that cyclical variation in proprietary income is an indicator of uninsurable background risk, cpy should therefore help to predict excess stock returns.

Table 5 provides results from univariate long horizon regressions of excess returns on stock market wealth onto the cpy residual. Panel I of table 5 reports long-horizon regressions of excess returns in the Standard \& Poor's (S\&P) 500 index on cpy. The temporary component of proprietary income significantly predicts excess returns at horizons of two years and beyond. The associated $R^{2}$ coefficients at the two year horizon are 0.10 . But the forecasting power of cpy seems to be concentrated at longer horizons, at the 6 year (24 quarters) horizon, cpy accounts for more than fifty percent in the variability of excess returns.

Panel II reports the same univariate regressions, but now based on excess returns on the CRSP index. The CRSP is a much broader index than the $\mathrm{S} \& \mathrm{P}$. While the pattern of results is exactly the same as that obtained for the $\mathrm{S} \& \mathrm{P}$, it is noteworthy that the associated $t$-statistics and $R^{2}$ measures are somewhat lower throughout than for the S\&P. While this result should not be overemphasized, it is consistent with an interpretation of cpy as a measure of uninsurable entrepreneurial risk once one recognizes that excess returns on the S\&P 500 are slightly less volatile than are those on the CRSP index: since proprietors have larger background risk than the average investor, their stock portfolios should be biased towards a narrower group of standard shares that may be slightly less risky. Note also that all coefficients are positively signed, consistent with the uninsurable background risk story: cpy and expected returns are positively correlated, so that proprietary income below trend predicts rising expected returns. 


\subsection{Comovement with corporate earnings and dividends}

Proprietary income could of course help to predict stock market returns for reasons that are unrelated to the background-risk and non-participation mechanism that provides the motivation for this paper. First, proprietary income could be correlated with corporate earnings over the business cycle. Secondly, proprietary income is the dividend from proprietary wealth, so one may expect a correlation with corporate dividends. I explore both of these mechanisms in turn.

The first of these mechanisms can easily be ruled out: the results in panel III of table 5 suggest that cpy does not predict aggregate earnings of S\&P 500 companies. Only at the six year horizon would the relationship appear marginally significant.

Interestingly, while cpy cannot predict earnings, it does predict corporate dividends: panel IV of the same table shows long horizon regressions of dividend payments on the S\&P 500. The cpy residual has predictive power for dividend growth at business cycle frequencies, i.e. horizons from 3-6 years. This result seems remarkable since dividend growth has generally been found hard to predict by financial variables, at least over longer horizons. Only recently some authors, notably Lettau and Ludvigson (2003) have started to report that dividend growth does indeed seem predictable at business cycle frequencies from variables such as the consumption income ratio. Lettau and Ludvigson (2003) identify a cointegrating relationship between consumption, corporate dividends and labour income and find dividends to be predictable at the same horizons as I do.

The fact that I find dividends to be predictable may however seem particularly surprising since my measure of other income, $y$, includes dividend payments and since the results in the previous section showed that the loading coefficient of $y$ on the cointegrating relationship cpyt is insignificant in the VECM.,This suggests that cpy does not predict other income as a whole. Long horizon regressions of other income on $c p y_{t}$ (not reported) reveal the same outcome.

To explore this issue further, I construct a measure of 'other income' exclusive of dividends. Excluding dividend payments does not change the results for the cointegrating relations or for the VECM: cointegration tests still reveal a cointegrating relationship between $c, p$ and $y$ and the cointegrating relationship mainly reflects error correction in proprietary income. Still, this alternative measure of cpy predicts dividend growth in long-horizon regressions. Furthermore, using the broader concept of dividends from the BEA personal income tables rather than just the dividend data strengthens the results. In the long-horizon regressions in Panel $\mathrm{V}$, the dependent variable 
is personal dividend income from the national income and product accounts and cpy is constructed without dividend income. In this regressions, dividends are predictable even at horizons as low as 2 years.

As shown in Lettau and Ludvigson (2003), dividends also have some forecasting power for excess returns. So it could indeed be the case that proprietary income predicts stock returns only because it is incidentally correlated with corporate dividend payments. To address this issue, I follow Lettau and Ludvigson (2003) and consider a cointegrating relationship between consumption, dividend income and labour income. My estimate of this cointegrating relationship is

$$
c d y_{t}=c_{t}-0.21 d_{t}-0.68 y_{t}
$$

and again in analogy to Lettau and Ludvigson I refer to it as $c d y$. As shown in Lettau and Ludvigson, fluctuations in this cointegrating relationship can largely be associated with fluctuations in dividends, a result also borne out in my data, when I estimate a VECM in $\Delta c, \Delta d$ and $\Delta y$.

I then regress excess returns and dividends on both cpy and $c d y$. These results are reported in table 6: When considered individually , cdy has forecasting power for both dividends (first regression in panel I) and excess returns (first regression in panel II) at horizons beyond 2 years. This is very similar to the findings reported by Lettau and Ludvigson.

When cpy is added as a second regressor, cdy continues to predict dividends at rather short horizons (panel I). But panel II also clearly shows that $c d y$ becomes insignificant in the forecasting regression for stock returns at all horizons. The adjusted $R^{2}$-measure for this regression is almost identical to the one obtained from the univariate regression of excess returns on cpy alone that was reported in table 5, panel I and a lot higher than that attained for $c d y$ alone. Interestingly, cpy is now significant at all horizons.

The results in this subsection show that, while cpy is correlated with dividends over the business cycle, variation in dividends is not the source of the predictive power of cpy for stock returns. The ability of cpy to predict stock returns by far exceeds that of $c d y$ even though $c d y$ is the better predictor of dividends.

\subsection{How much of the predictive power of the consumption- wealth ratio can cpy explain?}

The empirical fact that the consumption-wealth ratio (cay) predicts excess returns is consistent with a broad range of economic models that all allow to rationalize time variation in expected returns. In this section, I address 
the question to what extent variation in entrepreneurial background risk - as measured by the transitory component of proprietary income - can explain the predictive power of the consumption-wealth ratio. In table 7 , I therefore turn to multivariate long horizon regressions of excess returns on the S\&P500 ${ }^{2}$ on cpy $_{t}$ and cay along with other ususal suspect forecasting variables. It is well known that the consumption-wealth ratio crowds out the forecasting power of purely financial forecasting variables. I therefore also asses to what extent this is the case for cpy.

In panel I, reports long-horizon regressions that, besides cpy, also include the cay residual as regressor. The consumption wealth ratio is significant at virtually all horizons, in line with the findings reported by Lettau and Ludvigson. But note that cpy, as the transitory part of proprietary income, continues to be significant at horizons of 3 years and beyond. The relative increase in the $R^{2}$ measure associated with the inclusion of cay into the regression decreases with the horizon. Whereas including cay in the set or regressors increases the explanatory power of the regression sixfold at the one quarter horizon (relative to the regression including only cpy in table 5, panel I), adding cay does not seem to make a difference at the 4-6 year horizon.

To answer the question how much more information is contained in cay than in cpy, panel II of table 5 represents the results of a regression of excess returns on cpy along with the usual suspect forecasting variables, plus a variable defined as res. It is this the residual from the regression of cay on cpy. This regression is highly significant but it only explains around 20 percent of the variability of cay, implying that the consumption wealth ratio reflects much more than just fluctuations in proprietary income.

The usual suspects forecasting variables included into the regressions reported in panel II of table 6 are the dividend-price ratio, the dividendearnings (payout) ratio as well as the cyclical (HP-detrended) component of the T-bill rate. The first feature that is apparent from the results in panel II of table 6 is that the usual suspects virtually add no information vis-a-vis the regressions in panel I. Virtually all coefficients are insignificant, with the notable exception of the payout ratio that appears just about significant at the six year horizon.

The second notable feature of the results is that replacing cay with res makes cpy significant at all horizons, but so remains res. On the one hand, this suggests that temporary fluctuations in proprietary income are an important source of time varying risk premia, possibly because fluctuations in the level of aggregate income from entrepreneurship go in hand with fluctu-

\footnotetext{
${ }^{2}$ The results for the CRSP are very similar and I therefore do not report them here.
} 
ations in non-insurable background risk. On the other hand, the very fact that res adds important information at all forecasting horizons also implies that the background risk associated with entrepreneurial income cannot be the entire story in rationalizing the size and variability of excess returns: at short horizons, cpy is clearly outperformed by cay.

\section{$5 \quad$ The changing link between entrepreneurial risk and the stock market}

The results in the previous sections support the notion that fluctuations in aggregate proprietary income are an indicator of entrepreneurial risk and that this factor is important in explaining the equity premium in the United States. However, the impact of entrepreneurial risk on aggregate pricing relations is likely to have changed over the sample period: the late 1970s and early 1980s mark a decline in the correlation between cpy - the transitory part of proprietary income - and cay - the transitory part of stock market wealth. The correlation between cay and cpy for the pre-1980 part of our sample is 0.69 , that for the post- 1980 period is only 0.21 . In this section, I examine how two important developments are likely to have contributed to this decline in correlation.

The first of these developments is that household access to stock markets has been gradually widening since the early 1980s: the share of households owning stocks increased from $19 \%$ in 1983 to $49.5 \%$ in 2002 . As argued by Poterba (1994), an important driver behind the increase in household stock ownership was was the growth of (employer-sponsored) 401(k) plans as a form of retirement savings. The number of households owning 401(k) plans rose from 4.4 million in 1983 to 20.4 million in 1993 and to $x x$ \{see if it's possible to get exact number $\}$ million in 2002. Equity accounts for a large share of the assets under administration in $401(\mathrm{k})$ plans. ${ }^{3}$ Since only employees are eligible for $401(\mathrm{k})$ plans, the role of proprietary income for the average stock owning household is likely to have declined.

A second development that is likely to to have diminished the role of proprietary income as a factor in explaining aggregate stock returns is that proprietary income has - at least in part - become more diversifiable through state level banking deregulation. Small, owner-run businesses are particularly dependent on bank-intermediated finance. As argued in Jayaratne and Strahan (1996), the removal of branching and interstate ownership restrictions on

\footnotetext{
${ }^{3}$ Poterba and Wise (1998) estimate that this share was between 40 and 60 percent in 1995.
} 
banks has led to a more efficient allocation of capital and better risk sharing between banks. Jayaratne and Strahan (1996) present evidence that these efficiency gains are likely to have been passed on to banks' customers. Bank loans effectively work as a risk sharing device since they allow the firm to smooth temporary fluctuations in cash flow. Recent results by Demyanyk, Ostergaard and Sørensen (2004) show that state level personal income has indeed become less sensitive to state level shocks after banking deregulation. They also show that this decline in the sensitivity of state-level personal income is driven mainly by a decline in the sensitivity of the proprietary income component of personal income. They find the decline in the sensitivity of state-level personal income to idiosyncratic output shocks to be more marked in states with a higher incidence of small businesses. This suggests that in particular small businesses have benefited from banking deregulation through better access to borrowing facilities. This, in turn, has made proprietary income risk more easily diversifiable. For the analysis in this paper this should imply that in the the wake of bank deregulation, proprietary income risk should have become less important in explaining stock market risk premia.

From eyeballing the raw data and the trend components in figure (3), it is also apparent that the decline in the correlation between cay and cpy coincides with a shift in the trend of proprietary income: after 1980, the average growth rate of proprietary income is 2.9 percent per year, compared to an annual 0.7 percent for the first half of the sample. The interpretation I wish to propose here is that this trend break is associated with state level bank deregulation: if the risks of entrepreneurial activity becomes more easily diversifiable, one would expect more entrepreneurial activity and ultimately higher growth rates in proprietary income. While cpy is the temporary deviation of proprietary income from its trend, this trend seems to have shifted due to banking deregulation and the correlation between cpy and stock markets has decreased.

To illustrate this point, I proxy the trend in proprietary income by scaling a linear trend with the exponential of the cumulative share of federal states that had fully deregulated at a given date. I label this scaled trend variable $C U M D E R E G .^{4}$ Figure (4) plots the raw series of proprietary income, the

\footnotetext{
${ }^{4}$ Specifically, $C U M D E R E G$ constructed as follows: I obtain data on state level banking deregulation from table (1) in Demyanik, Ostergaard and Sørensen (2004). For each state, this data set contains the year of intra-state branching deregulation as well as the year of liberalization of interstate bank holding regulation. This allows me to obtain a time series for the percentage of federal states that had fully deregulated in a given year. To obtain a quarterly series, the observations for each quarter are then set equal to the annual percentage, so that a step function is obtained. I then construct $C U M D E R E G$ as
} 
fitted value of the regression of proprietary income on a linear trend and the fitted value of a regression on $C U M D E R E G$. By way of comparison, the figure also replicates the stochastic trend obtained from the cointegrated VAR that already appeared in figure (3). During the period of banking deregulation, i.e. mainly the 1980 s and early $1990 \mathrm{~s}^{5}, C U M D E R E G$ does a good job at capturing the shift in the stochastic trend estimated earlier. The same message comes from Figure 5 that plots the normalized residual of the regression on $C U M D E R E G$ along with the normalized cpy residual: excluding observations after 1990, the correlation between the two time series is 0.74 . The correlation over the 1980 s alone, i.e. the period during which most federal states deregulated, is even higher at almost $0.9 .^{6}$

To develop an idea of the joint importance of the two developments increasing stock market participation and state level banking deregulation for the link between cay and cpy, I calculate a time series of moving-window correlations between these two residuals. I refer to this time series as $C O R R$. $^{7}$ Figure (5) plots CORR along with cay and cpy. The marked decline in the correlation between cay and cpy after1980 shows up very clearly. But it is also worth noting that the correlation also slowly increases again after 1990 .

In a next step, I run various regressions of $C O R R$ on the share of states that had deregulated at a given time and on a second variable, the share of U.S. households owning stocks. ${ }^{8}$ Note that the deregulation variable is based on the year in which a state fully completed deregulation. Hence, the effects of deregulation on the correlation between cpy and cay are likely to be felt well ahead of the deregulation variable actually registering an increase.

the exponential of this step function multiplied with a linear trend.

${ }^{5}$ The Riegle-Neal Act of 1994 allows interstate branching and banking. Even though individual states were allowed to opt out from this federal legislation, only very few states did so, implying that most states had effectively deregulated by the mid-990s.

${ }^{6}$ While $C U M D E R E G$ has a permanent effect on the trend growth rates of proprietary income, it can only in part account for the continued high growth of proprietary income after the completion of banking deregulation in the early 1990s. But note that banking deregulation is likely to continue to lead to changes in market structure in the banking sector even after it is formally completed. Therefore, the impact of banking deregulation on trend growth in proprietary income is also likely to continue, at least for a while. Numbers from the Small Business Administration, lending to small businesses continued to expand substantially throughout the 1990s. Clearly, by the very way it is constructed, the variable $C U M D E R E G$ cannot capture this effect.

${ }^{7}$ The correlation is taken over twenty quarters respectively so that $C O R R_{t}=$ $\operatorname{corr}\left(\operatorname{cay}_{t-40: t}\right.$, cpy $\left._{t-40: t}\right)$.

${ }^{8}$ Data on the percentage of U.S. households owning stocks is available on an irregular basis from Equity Ownership in America (ICI and SEA 2002). I used observations for 1983, 1996, 1999 and 2002 which I then linearly interpolated. Observations before 1983 were set to the observation for 1983 . 
I therefore use an 8 quarter lead instead of the contemporary value of this variable in this regression, the results of which are summarized in table (8). The first two columns report on separate regressions of CORRon the banking deregulation and participation variables. In both cases, the coefficients are signed as expected and highly significant, the regression on the deregulation variable alone explains more than 40 percent of the variability in $C O R R$. The third column reports the multiple regression of $C O R R$ on both the deregulation as well as the participation variables. Now, the adjusted $R^{2}$ reaches more than 80 percent. Again both coefficients are significant, but the coefficient on stock market participation suggests that increasing stock market participation increases rather than lowers the correlation between cay and cpy. In the data, the icrease in the correlation between cay and cpy towards the end of the sample period coincides with the technology boom of the 1990s, a period in which venture capital and other forms of business finance saw a big boom. The generally favourable climate in financial markets could therefore have interacted with improved financing conditions for small businesses. To capture this idea, I therefore also include an interaction term between stock market participation and banking deregulation in the regression reported in column (4). Again, all coefficients are highly significant, the adjusted $R^{2}$ exceeds 0.9 , but now the coefficient on the stock market particpation trend is negative as expected, while it is now the coefficient on the interaction term that, indeed, captures the increase in $C O R R$ throughout the 1990s.

Figure (6) plots the fitted value of this last regression against $C O R R$. The simple model does very well in capturing the decline of $C O R R$ and its subsequent recovery. To allow for the possibility that $C O R R$ as well as the two regressors are non-stationary but cointegrate, I also conducted a unitroot test on the regression residual. These tests lead me to reject the unit root, suggesting that - if characterized as a unit-root process - CORR would indeed seem to cointegrate with the two trend variables.

The main result of this section is that the decline in the correlation between cpy and cay after 1980 can be statistically associated with the growth of stock market participation and with improvements in small firms' access to credit markets and therefore to insurance. This strengthens the interpetation of the findings in this paper in the light of the entrepreneurial income risk mechanism: this mechanism effectively interacts two theoretical ingredients - limited participation in stock markets and non-insurable background risk for those households that participate. Entrepreneurial income risk appears to have played an important part in explaining variations in expected U.S. stock market returns over the post war period. But as access to stock markets has widened and as proprietary income risk has become more diversifiable in the 
wake of banking deregulation, the mechanism has become less important very much as economic theory would suggest.

\section{Discussion and Conclusion}

This paper has identified proprietary income as a major predictable component of personal income in U.S. data. Transitory variation in proprietary income is highly correlated with fluctuations in the consumption-wealth ratio and has considerable predictive power for excess stock market returns as well as for dividends.

What drives these results? A simple explanation could be that proprietary income is likely to be highly correlated with corporate earnings over the business cycle. But I find earnings are hardly predictable from the temporary component of proprietary income as it is identified in this paper. While proprietary income, as the dividend from proprietary wealth, comoves substantially with corporate dividends, it substantially outperforms dividends in predicting stock returns. Furthermore, the cyclical variation of aggregate proprietary income is highly correlated with the cross-sectional variance of growth rates in proprietary income at the federal state-level.. One way in which I suggest to interpret the present set of findings is as evidence for a model of asset prices in which entrepreneurial risk drives variation in risk aversion and hence risk premia.

Since the work of Lettau and Ludvigson (2001, 2004), it is known that the ratio between consumption and aggregate wealth has considerable forecasting power for excess returns on stocks. This finding raises the question what the theoretical levers are that can explain temporary fluctuations in asset prices: is it habit formation as in Campbell and Cochrane (1999) or is the story one of uninsurable background risk, as in Heaton and Lucas (2000)?

While I find that temporary fluctuations in proprietary income are an important source of variation in the aggregate consumption wealth ratio, the temporary component of proprietary income cannot completely drive out the consumption wealth ratio as a predictor of excess stock returns. In particular, the consumption-wealth ratio outperforms proprietary income at rather short horizons, whereas proprietary income matters most at horizons of 3 to 6 years. This suggests that uninsurable background risk - even when coupled with limited stock participation, as is in the case in the entrepreneurial background risk mechanism - cannot be the entire story of why risk premia fluctuate over the business cycle. Furthermore, the predictive power of proprietary income for stock returns has decreased in line with wider access of private households to stock markets and with better access of small business to insurance through 
bank loans.

The results in this paper also contribute to a recent literature that has started to uncover important transitory components in dividend growth at the business cycle frequency. Lettau and Ludvigson (2003) have identified a cointegrating relationship between consumption, dividend and labour income and find that the cointegrating residual does indeed predict dividend growth at horizons between three and six years. Their findings help to understand why the dividend-price ratio typically fails to predict changes in dividends at the business cycle frequency: both dividends and excess returns covary positively at the business cycle frequency and these effects seem to offset in the dividend price ratio. Using the temporary component of proprietary income as a forecasting variable, the present paper comes to very similar conclusions.

One interesting novel feature of the results presented here is that the forecasting variable I use does not include the past of the variable that is to be predicted: the approximation of the consumption wealth ratio used by Lettau and Ludvigson $(2001,2004)$ reflects an ingenious way of identifying the transitory component of stock market wealth using a theory-based variable. The same is true of the consumption-dividend income ratio. But both cay and the consumption-dividend income ratio $(c d y)$ are themselves functions of stock market prices and dividends respectively. Proprietary income, however, is not by construction a function of either stock market prices or dividends. This feature makes the findings in this paper informative with respect to the particular transmission mechanism between the consumptionwealth ratio and risk premia in financial markets.

\subsection{Summary}

This paper has shown that the transitory part of proprietary income has had considerable predictive power for excess returns in the U.S. stock market over much of the postwar period. Proprietary income also predicts dividends but not corporate earnings at business cycle frequencies. Over the postwar period, its ability to forecast excess stock returns considerably exceeds that of corporate dividends. At the same time, the cyclical component of proprietary income correlates negatively with cross-sectional measures of entrepreneurial risk. These findings are consistent with the mechanism suggested by Heaton and Lucas (2000a, 2000b): proprietary income is an important source of non-insurable background risk for those (generally wealthy) households that participate in the stock market. To the extent that fluctuations in average proprietary income capture fluctuations in entrepreneurial risk, they are therefore likely to enter aggregate asset pricing relations. The evi- 
dence reported in this paper also suggests that the role of the entrepreneurial background risk mechanism in explaining stock returns has decreased to the extent that stock market participation of private, non-proprietor households in the U.S. has widened and to the extent that state-level banking deregulation has facilitated the sharing of proprietary income risk. To my knowledge, my results constitute the first time-series evidence on the role of this mechanism in postwar U.S. stock markets.

An alternative way to read the paper is as an attempt to quantify econometrically to what extent the predictive power of the consumption wealth ratio for equity premia can be explained by one particular mechanism that has attracted a lot of attention in the recent literature. My findings suggest that entrepreneurial risk can explain a considerable amount of the predictable variation at horizons beyond three years but that it fails to explain predictable variation at short horizons. Additional mechanisms, such as habit formation along the lines of Campbell and Cochrane (1999) are therefore likely to be needed to explain the forecasting power of the consumption-wealth ratio for excess returns on stocks.

The findings in this paper are also potentially useful for our understanding of the allocation of consumption risk across regions and countries. Agronin (2004) reports that consumption risk sharing among U.S. federal states decreases during booms and increases during recessions. He identifies imperfect sharing of proprietary income risks as the main source of this variation. My findings here suggest that proprietary income is indeed the least smoothed component of personal income in US aggregate data. It will be interesting to investigate how federal states smooth idiosyncratic fluctuations in proprietary income. I leave this for future research.

\section{References}

[1] Agronin, Eugene (2004). 'Risk Sharing across the United States, Proprietary Income and the Business Cycle', manuscript, Harvard University.

[2] Brennan, Michael and Yihong Xia (2002), "tay's as good as cay," unpublished paper, Anderson School of Business, University of California, Los Angeles.

[3] Campbell, John Y., and J. Cochrane, (1999). 'By Force of Habit: A Consumption-Based Explanation of Aggregate Stock Market Behavior' Journal of Political Economy 107, 205-51. 
[4] Campbell, John Y. and Gregory N. Mankiw (1989). 'Consumption, Income, and Interest Rates: Reinterpreting the Time Series Evidence,' in NBER Macroeconomics Annual: 1989, ed. by O. Blanchard, and S. Fischer, pp. 185-216. MIT Press, Cambridge, MA.

[5] Cochrane, John H. (1994). 'Permanent and Transitory Components of GDP and Stock Prices.' Quarterly Journal of Economics 109, 241-265.

[6] Cochrane, John H. (2001). Asset Pricing, Princeton NJ: Princeton University Press.

[7] Constantinides, George (1990). 'Habit Formation: a resolution of the equity premium puzzle.' Journal of Political Economy, vol. 98, 519-43.

[8] Constantinides, George and Darrell Duffie (1996). 'Asset Pricing with Heterogeneous Consumers', Journal of Political Economy 104(2), 21940.

[9] Demyanyk, Yuliya, Charlotte Ostergaard and Bent E. Sørensen (2004). 'U.S. Banking Deregulation, Small Businesses and Interstate Insurance of Personal Income', manuscript dated December 2004, University of Houston.

[10] Fama, Eugene F. and Kenneth R. French (1993). 'The Cross-Section of Expected Returns.' Journal of Finance 47, 427-465.

[11] Gertler, M., and R. G. Hubbard (1993). 'Corporate Financial Policy, Taxation, and Macroeconomic Risk,' Rand Journal of Economics, 24(2), 286-303.

[12] Gonzalo, Jesus and Granger, Clive W., (1995), 'Estimation of Common Long-Memory Components in Cointegrated Systems,' Journal of Business and Economics Statistics 13: 27-35.

[13] Heaton, John and Deborah Lucas (2000 a) 'Portfolio Choice in the Presence of Background Risk' Economic Journal, vol 110, 1-26.

[14] Heaton, John and Deborah Lucas (2000 b). 'Portfolio Choice and Asset Prices: The Importance of Entrepreneurial Risk' Journal of Finance, vol 55, 1163-1198.

[15] Hoffmann, Mathias (2001). "Long Run Recursive VAR Models and QR Decompositions.", Economics Letters, vol. 73 no. 1 (October), pp. 15-20. 
[16] Jayaratne, Jith and Philip E. Strahan (1996), 'The finance-growth nexus: Evidence from bank branch deregulation', Quarterly Journal of Economics, 11, 639-670.

[17] Johansen, Søren, (1995), Likelihood-based inference in cointegrated vector autoregressive models. Oxford University Press: Oxford.

[18] Johansen, Søren, (1997). 'Common Trends in the Cointegrated VAR model.' mimeo, European University Institute.

[19] Lamont, O. (1998). 'Earnings and Expected Returns,' Journal of Finance, $53,1563-87$.

[20] Lettau, Martin and Sidney Ludvigson (2001). 'Consumption, Aggregate Wealth and Expected Stock Returns', Journal of Finance, LVI (3), 815849.

[21] Lettau, Martin and Sidney Ludvigson (2003). 'Expected Returns and Expected Dividend Growth', Journal of Financial Economics, forthcoming.

[22] Lettau, Martin and Sidney Ludvigson (2004). 'Understanding Trend and Cycle in Asset Values: Reevaluating the Wealth Effect on Consumption.' forthcoming, American Economic Review.

[23] Mankiw, Gregory N. and Stephen P. Zeldes, 1991. 'The Consumption of Stockholders and Non-Stockholders', Journal of Financial Economics, Vol. 27, pp. 97-112, (1991).

[24] Moskowitz, Tobias J. and Annette Vissing-Jørgensen (2002). 'The Returns to Entrepreneurial Investment: A Private Equity Premium Puzzle?', vol 92(4), pp. 745-777.

[25] Polkovnichenko, Valery (2004). 'Limited Stock Market Participation and the Equity Premium', Finance Research Letters, vol. 1, no. 1.

[26] Poterba (1994)

[27] Poterba, James, Venti, Steven F. and David Wise (1994). 'Do 401(k) Crowd Out Other Private Saving?', Journal of Public Economics, 58 (September), 1-32.

[28] Poterba, James, Venti, Steven F. and David Wise (1998). '401(k) Plans and Future Patterns of Retirement Saving,' American Economic Review, $88,315-320$. 
[29] Proietti, Tomaso (1997), 'Short-Run Dynamics in Cointegrated Systems,' Oxford Bulletin of Economics and Statistics 59: 405-422.

[30] Rudd, Jeremy B. and Karl Whelan (2002). "A Note on the Cointegration of Consumption, Income, and Wealth". FEDS Working Paper No. 200253. http://ssrn.com/abstract $=361261$

[31] Stock, James H., and Mark Watson, (1993). 'A simple estimator of cointegrating vectors in higher order integrated systems', Econometrica $6,783-820$.

[32] Vissing-Jørgensen, Annette (2002). 'Limited Stock Market Participation and the Equity Premium Puzzle', Ph.D. thesis chapter, MIT. Published as 'Limited Stock Market Participation and the Elasticity of Intertemporal Substitution', Journal of Political Economy, August 2002, vol. 110, no. $4,825-853$. 


\section{Technical Appendix}

Note that $\Psi_{t}$ is the present value of all dividends, $\Psi_{t}=C_{t}+\sum_{k=1}^{\infty}\left[\prod_{s=1}^{k} R_{C, t+s}\right]^{-1} C_{t+k}$ where $R_{C, t+s}$ is the gross return on total wealth. This expression can be written recursively as

$$
\Psi_{t+1}=R_{C, t+1}\left(\Psi_{t}-C_{t}\right)
$$

which allows to use the approach adopted by Campbell and Mankiw (1989) for the log-linearization of the consumption-wealth ratio:

$$
\frac{\Psi_{t+1}}{\Psi_{t}}=R_{C, t+1}\left(1-\exp \left(c_{t}-\psi_{t}\right)\right)
$$

Taking logs yields

$$
\Delta \psi_{t+1}=r_{c, t+1}+\log \left(1-\exp \left(c_{t}-\psi_{t}\right)\right)
$$

The logarithmic term can now be expanded around the long-run consumptionwealth ratio $\exp (\overline{c-\psi})$ so that

$$
\begin{aligned}
\log \left(1-\exp \left(c_{t}-\psi_{t}\right)\right) & =\log (1-\exp (\overline{c-\psi}))+\frac{-\exp (\overline{c-\psi})}{(1-\exp (\overline{c-\psi}))}\left[c_{t}-\psi_{t}-\overline{c-\psi}\right] \\
& =\kappa_{C}-\frac{\exp (\overline{c-\psi})}{(1-\exp (\overline{c-\psi}))}\left[c_{t}-\psi_{t}\right]
\end{aligned}
$$

where

$$
\kappa_{C}=\log (1-\exp (\overline{c-\psi}))+\frac{\exp (\overline{c-\psi})}{(1-\exp (\overline{c-\psi}))} \overline{c-\psi}
$$

Write $\Delta \psi_{t+1}$ tautologically as

$$
\Delta \psi_{t+1}=\Delta c_{t+1}-\left(c_{t+1}-\psi_{t+1}\right)+\left(c_{t}-\psi_{t}\right)
$$

to obtain

$$
\begin{aligned}
& \kappa_{C}+r_{c, t+1}+\left[1-\frac{1}{\rho}\right]\left[c_{t}-\psi_{t}\right] \\
= & \Delta c_{t+1}-\left(c_{t+1}-\psi_{t+1}\right)+\left(c_{t}-\psi_{t}\right)
\end{aligned}
$$

where $\rho_{c}=1-\exp (\overline{c-\psi})$. Then rearrange to obtain

$$
\kappa_{C}+\frac{1}{\rho}\left[c_{t}-\psi_{t}\right]=r_{c, t+1}-\Delta c_{t+1}-\left(c_{t+1}-\psi_{t+1}\right)
$$


which, can be solved forward with $\rho_{c}^{k}\left(c_{t+k}-\psi_{t+k}\right) \rightarrow 0$ to get

$$
\left[c_{t}-\psi_{t}\right]=\frac{\rho_{c}}{1-\rho_{c}} \kappa_{c}+\sum_{k=1}^{\infty} \rho_{c}^{k}\left[r_{c, t+1}-\Delta c_{t+1}\right]
$$

If consumption and wealth are both integrated $(I(1))$ process, then $\Delta c$ will be stationary. Assuming that returns are also stationary, the right hand side of this present-value relation reflects the discounted sum of stationary variables and will therefore be stationary. Hence, $c_{t}-\psi_{t}$ is stationary. get

Applying the same log-linearization procedure to $p_{t}-\pi_{t}$, and $y_{t}-\theta_{t}$, I

$$
\begin{aligned}
& \psi_{t}=c_{t}+\mathbf{E}_{t} \sum_{k=1}^{\infty} \rho_{c}^{k}\left(\Delta c_{t+k}-r_{C, t+k}\right) \\
& \pi_{t}=p_{t}+\mathbf{E}_{t} \sum_{k=1}^{\infty} \rho_{p}^{k}\left(\Delta p_{t+k}-r_{P, t+k}\right) \\
& \theta_{t}=y_{t}+\mathbf{E}_{t} \sum_{k=1}^{\infty} \rho_{y}^{k}\left(\Delta y_{t+k}-r_{Y, t+k}\right)
\end{aligned}
$$

where $\rho_{x}$ is the mean reinvestment ratio of the respective wealth component, e.g. $\rho_{c}=1-\exp (\overline{c-\psi})$.Plugging into (4) one then obtains the desired relation between $c, p$ and $y$.

Note that $r_{C, t+k}$ can be interpreted as the return on total wealth, which is the weighted average of returns on proprietary and other forms of wealth, so that approximately

$$
r_{C, t+k} \approx \gamma r_{P, t+k}+(1-\gamma) r_{Y, t+k}
$$

To see that cpy must be a cointegrating relationship, plug in relations (5) and (6) into the linearized budget constraint (3). Then rearrange the forward looking terms to the right so that

$$
\begin{aligned}
c p y= & -(1-\gamma) \kappa+\gamma E_{t} \sum_{k=1}^{\infty}\left(\rho_{p}^{k} \Delta p_{t+k}+\left(\rho_{c}^{k}-\rho_{p}^{k}\right) r_{P, t+k}\right) \\
& +(1-\gamma) E_{t} \sum_{k=1}^{\infty}\left(\rho_{y}^{k} \Delta y_{t+k}+\left(\rho_{c}^{k}-\rho_{y}^{k}\right) r_{Y, t+k}\right)-E_{t} \sum_{k=1}^{\infty} \rho_{c}^{k} \Delta c_{t+k}
\end{aligned}
$$

From this representation it is apparent that cpy must be stationary: since $c, p$ and $y$ are all best characterized as individually $I(1)$, the present value of 
their changes must be stationary. If the returns on wealth are stationary, then their discounted sum must equally be stationary. This implies that cpy will be stationary. It therefore defines a cointegrating relationship that measures the temporary deviation of consumption, proprietary and other income from the common trends.

The deviation of the cointegrating relation from its long-run mean then predicts changes in either consumption or in one of the two components of income: away from the long-run trend, at least one of the three variables will have to adjust.

But note also that according to (7), cpy may also predict returns on the different components of wealth, $r_{X t+k}$, if $\rho_{c}-\rho_{y}$ and $\rho_{c}-\rho_{p}$ do not vanish. The intuition for this becomes clear once one reconsiders that the $\rho$-coefficients reflect the reinvestment ratios (or one minus the long-run dividend-wealth ratio) for the different forms of wealth. $\rho_{c}$ is the long-run mean of the consumption- total wealth ratio. If the reinvestment ratio on e.g. other income is lower than that on total wealth, then the cointegrating relation may also predict the returns on non-proprietary wealth (e.g. stocks). The reason for this is that a long-run constant share of non-proprietary wealth in total wealth and higher than average dividend payments on non-proprietary wealth will be possible only if the returns on non-proprietary wealth are increasing in the future. 


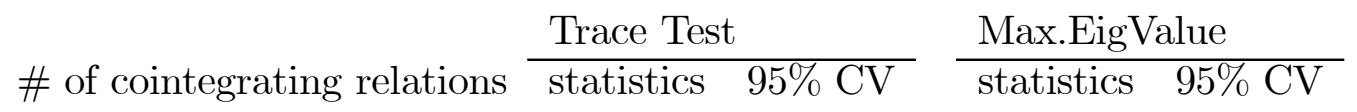

\begin{tabular}{|c|c|c|c|c|}
\hline & Panel I: I & Durak & Consumpt & \\
\hline$h=1$ & 42.01 & 31.25 & 34.13 & 21.27 \\
\hline$h=2$ & 7.97 & 17.84 & 7.82 & 14.59 \\
\hline$h=3$ & 0.15 & 8.08 & 0.15 & 8.08 \\
\hline \multicolumn{5}{|c|}{ Panel II: Total Consumption } \\
\hline$h=1$ & 31.9736 & & 22.9592 & \\
\hline$h=2$ & 9.0145 & & 8.9895 & \\
\hline$h=2$ & 0.0250 & & 0.0250 & \\
\hline
\end{tabular}

Table 2: estimated cointegrating vectors

Non-Durables Consumption

Johansen Dynamic OLS

$\begin{array}{lcccc}\beta_{c} & 1 & 1 & 1 & 1 \\ \beta_{p} & -0.2697 & -0.2713 & -0.2578 & -0.2623 \\ \beta_{y} & -0.8099 & -0.8148 & -0.7606 & -0.7641\end{array}$

NOTES:Estimates of the cointegrating vector $\beta=\left[\begin{array}{lll}1 & \beta_{p} & \beta_{y}\end{array}\right]^{\prime}$. The estimate from the Johansen-procedure is based on a VECM with one lagged difference term and an unrestricted intercept. The Dynamic OLS regression is of the form $c_{t}=\mu-\beta_{p} p_{t}-\beta_{y} y_{t}+\sum_{l=-k}^{k} a_{l} \Delta p_{t-l}+b_{l} \Delta y_{t-l}+u_{t}$ where $k=3$ leads and lags have been chosen. 
Table 3: Estimated VECM

\begin{tabular}{cccc}
\hline \multirow{4}{*}{ Equation } & \\
\cline { 2 - 4 } & $\Delta c_{t}$ & $\Delta p_{t}$ & $\Delta y_{t}$ \\
$\Delta c_{t-1}$ & $\mathbf{0 . 2 5 7 6}$ & $\mathbf{0 . 9 2 4 9}$ & $\mathbf{0 . 6 8 0 8}$ \\
& $(3.4969)$ & $(3.0775)$ & $(4.5223)$ \\
$\Delta p_{t-1}$ & 0.0144 & $\mathbf{0 . 1 5 3 8}$ & -0.0602 \\
& $(0.7874)$ & $(2.0646)$ & $(-1.6123)$ \\
$\Delta y_{t-1}$ & 0.0487 & -0.0659 & 0.0252 \\
& $(1.1738)$ & $(-0.3890)$ & $(0.2976)$ \\
$c p y_{t-1}$ & -0.0216 & $\mathbf{0 . 3 3 8 8}$ & 0.0355 \\
& $(-1.2518)$ & $(4.8105)$ & $(1.0066)$
\end{tabular}

NOTES: t-statistics in parentheses, coefficients significant at the $5 \%$ level are in bold-face. $c p y=c-0.2713 p-0.8148 y$.

Table 4: Variance decompositions

Variance share of transitory component

Horizon $k$ in quarters

\begin{tabular}{lllllllll} 
& \multicolumn{8}{c}{ Horizon $k$ in quarters } \\
\hline & 1 & 2 & 4 & 8 & 12 & 16 & 24 \\
$c_{t+k}-\mathbf{E}_{t}\left(c_{t+k}\right)$ & 0.04 & 0.03 & 0.02 & 0.01 & 0.01 & 0.004 & 0.003 \\
$p_{t+k}-\mathbf{E}_{t}\left(p_{t+k}\right)$ & 0.64 & 0.52 & 0.42 & 0.32 & 0.25 & 0.19 & 0.13 \\
$y_{t+k}-\mathbf{E}_{t}\left(y_{t+k}\right)$ & 0.03 & 0.01 & 0.01 & 0.002 & 0.002 & 0.001 & 0.001 \\
& & & & & & & \\
\hline
\end{tabular}


Table 5: Univariate Long-horizon regressions on cpy

\begin{tabular}{|c|c|c|c|c|c|c|c|c|}
\hline & & & $\begin{array}{r}{ }_{l=1}^{k} \Delta q_{t+l} \\
\text { Horizo }\end{array}$ & $\begin{array}{l}=\delta_{k} c p \\
k \text { in }\end{array}$ & $\begin{array}{l}+\mu_{k}+ \\
\text { arters }\end{array}$ & & & \\
\hline & 1 & 2 & 4 & 8 & 12 & 16 & 24 & \\
\hline & Pane & I: exces & returns & $\mathrm{n} \mathrm{S} \& \mathrm{P}$ & $00-\Delta q$ & $l=r_{t+}$ & $-r_{t+l}^{f}$ & \\
\hline $\begin{array}{l}\delta_{k} \\
\frac{t \text {-stat }}{R^{2}}\end{array}$ & $\begin{array}{l}0.36 \\
(1.33)\end{array}$ & $\begin{array}{l}0.67 \\
(1.34)\end{array}$ & $\begin{array}{l}1.38 \\
(1.43)\end{array}$ & $\begin{array}{l}\mathbf{3 . 4 7} \\
(2.53)\end{array}$ & $\begin{array}{l}\mathbf{6 . 0 6} \\
(3.98)\end{array}$ & $\begin{array}{l}\mathbf{7 . 8 2} \\
(4.76)\end{array}$ & $\begin{array}{l}\mathbf{1 2 . 4 8} \\
(5.88)\end{array}$ & \\
\hline & {$[0.01]$} & & & & & & {$[0.52]$} & $\mathrm{x}$ \\
\hline & Pan & II: exc & ss return & on $\mathrm{CR}$ & $\mathrm{P}-\Delta q_{t}$ & $l=r_{t+}$ & $-r_{t+l}^{f}$ & \\
\hline $\begin{array}{l}\delta_{k} \\
\frac{t \text {-stat }}{R^{2}}\end{array}$ & $\begin{array}{l}0.47 \\
(1.67) \\
{[0.01]}\end{array}$ & $\begin{array}{l}0.79 \\
(1.43) \\
{[0.01]}\end{array}$ & $\begin{array}{l}1.28 \\
(1.23) \\
{[0.02]}\end{array}$ & $\begin{array}{l}\mathbf{3 . 2 2} \\
(2.11) \\
{[0.09]}\end{array}$ & $\begin{array}{l}\mathbf{5 . 4 1} \\
(3.28) \\
{[0.21]}\end{array}$ & $\begin{array}{l}\mathbf{6 . 8 7} \\
(4.20) \\
{[0.30]}\end{array}$ & $\begin{array}{l}\mathbf{1 0 . 8 3} \\
(5.23) \\
{[0.46]}\end{array}$ & \\
\hline & & nel III: & Earnings & $\mathrm{n} \mathrm{S \& P}$ & $500-\Delta$ & $+l=\Delta$ & & \\
\hline $\begin{array}{l}\delta_{k} \\
\frac{t \text {-stat }}{R^{2}}\end{array}$ & $\begin{array}{l}-0.38 \\
(-1.65) \\
{[0.02]}\end{array}$ & $\begin{array}{l}-0.54 \\
(-1.09) \\
{[0.01]}\end{array}$ & $\begin{array}{l}-0.21 \\
(-0.21) \\
{[-0.004]}\end{array}$ & $\begin{array}{l}1.27 \\
(0.90) \\
{[0.01]}\end{array}$ & $\begin{array}{l}2.74 \\
(1.87) \\
{[0.05]}\end{array}$ & $\begin{array}{l}3.20 \\
(1.78) \\
{[0.06]}\end{array}$ & $\begin{array}{l}\mathbf{4 . 4 6} \\
(2.26) \\
{[0.12]}\end{array}$ & \\
\hline & & nel IV: & ividends & on S\&I & $500-\Delta$ & $t+l=\angle$ & $\bar{l}_{t+l}$ & \\
\hline $\begin{array}{l}\delta_{k} \\
\frac{t \text {-stat }}{R^{2}}\end{array}$ & $\begin{array}{c}0.01 \\
(0.09) \\
{[-0.01]}\end{array}$ & $\begin{array}{c}0.04 \\
(0.29) \\
{[-0.004]}\end{array}$ & $\begin{array}{c}0.18 \\
(0.74) \\
{[0.002]}\end{array}$ & $\begin{array}{c}0.90 \\
(1.76) \\
{[0.06]}\end{array}$ & $\begin{array}{l}\mathbf{1 . 7 2} \\
(2.47) \\
{[0.13]}\end{array}$ & $\begin{array}{l}\mathbf{2 . 2 1} \\
(2.56) \\
{[0.17]}\end{array}$ & $\begin{array}{l}\mathbf{3 . 3 7} \\
(3.05) \\
{[0.26]}\end{array}$ & \\
\hline Panel & Person: & Divides & d Incom & $-\Delta q_{t+l}$ & $=\Delta d_{t+l}$ & cpy $\mathrm{co}$ & structed & ithout $d$ \\
\hline $\begin{array}{l}\delta_{k} \\
\frac{t \text {-stat }}{R^{2}}\end{array}$ & $\begin{array}{c}0.12 \\
(1.47) \\
{[0.01]}\end{array}$ & $\begin{array}{c}0.27 \\
(1.68) \\
{[0.01]} \\
\end{array}$ & $\begin{array}{l}\mathbf{0 . 5 8} \\
(2.26) \\
{[0.05]} \\
\end{array}$ & $\begin{array}{l}\mathbf{1 . 4 1} \\
(3.02) \\
{[0.14]}\end{array}$ & $\begin{array}{l}\mathbf{2 . 1 7} \\
(3.92) \\
{[0.23]} \\
\end{array}$ & $\begin{array}{l}\mathbf{2 . 5 0} \\
(3.23) \\
{[0.24]}\end{array}$ & $\begin{array}{c}\mathbf{3 . 6 3} \\
(3.88) \\
{[0.35]} \\
\end{array}$ & \\
\hline
\end{tabular}

NOTES: OLS regressions. $t$ - statistics (in round parentheses) are based on heteroskedasticity and autocorrelation consistent standard errors based on Newey and West (1987), using a window width of $k+1$. 
Table 6: Long-horizon regressions on $c p y$ and $c d y$

$$
\sum_{l=1}^{k} \Delta q_{t+l}=\delta_{k} c p y_{t}+\gamma_{k} c d y_{t}+\mu_{k}+v_{k t}
$$

$\mathbf{z}_{t} \quad$ Horizon $k$ in quarters

\begin{tabular}{|c|c|c|c|c|c|c|c|}
\hline & 1 & 2 & 4 & 8 & 12 & 16 & 24 \\
\hline \multicolumn{8}{|c|}{ Panel I:Dividend growth $-\Delta q_{t}=\Delta d_{t}$} \\
\hline cdy & $\begin{array}{l}0.20 \\
(2.44)\end{array}$ & $\begin{array}{l}0.42 \\
(2.76)\end{array}$ & $\begin{array}{l}0.89 \\
(2.97)\end{array}$ & $\begin{array}{l}1.73 \\
(3.44)\end{array}$ & $\begin{array}{l}2.59 \\
(4.60)\end{array}$ & $\begin{array}{l}3.31 \\
(5.62)\end{array}$ & $\begin{array}{l}4.23 \\
(8.06)\end{array}$ \\
\hline$\overline{R^{2}}$ & {$[0.04]$} & {$[0.09]$} & {$[0.17]$} & {$[0.28]$} & {$[0.39]$} & {$[0.50]$} & {$[0.58]$} \\
\hline cpy & $\begin{array}{l}-0.01 \\
(-0.07)\end{array}$ & $\begin{array}{c}-0.04 \\
(-0.24)\end{array}$ & $\begin{array}{l}0.08 \\
(0.27)\end{array}$ & $\begin{array}{l}0.66 \\
(1.32)\end{array}$ & $\begin{array}{l}1.17 \\
(2.31)\end{array}$ & $\begin{array}{l}1.04 \\
(1.50)\end{array}$ & $\begin{array}{l}1.65 \\
(2.53)\end{array}$ \\
\hline cdy & $\begin{array}{l}0.20 \\
(2.20)\end{array}$ & $\begin{array}{l}0.44 \\
(2.56)\end{array}$ & $\begin{array}{l}0.86 \\
(2.53)\end{array}$ & $\begin{array}{l}1.42 \\
(2.49)\end{array}$ & $\begin{array}{l}2.02 \\
(3.06)\end{array}$ & $\begin{array}{l}2.79 \\
(3.69)\end{array}$ & $\begin{array}{l}3.40 \\
(5.53)\end{array}$ \\
\hline$\overline{R^{2}}$ & {$[0.04]$} & {$[0.09]$} & {$[0.16]$} & {$[0.30]$} & {$[0.43]$} & {$[0.52]$} & {$[0.62]$} \\
\hline \multicolumn{8}{|c|}{ Panel II: Excess returns $-\Delta q_{t+l}=r_{t+l}-r_{t+l}^{f}$} \\
\hline cdy & $\begin{array}{r}0.04 \\
(0.20)\end{array}$ & $\begin{array}{r}0.05 \\
(0.14)\end{array}$ & $\begin{array}{r}-0.22 \\
(-0.30)\end{array}$ & $\begin{array}{r}-0.32 \\
(-0.24)\end{array}$ & $\begin{array}{r}1.19 \\
(0.91)\end{array}$ & $\begin{array}{r}3.10 \\
(1.96)\end{array}$ & $\begin{array}{r}6.11 \\
(2.62)\end{array}$ \\
\hline$\overline{R^{2}}$ & {$[-0.01]$} & {$[-0.01]$} & {$[-0.004]$} & {$[-0.004]$} & {$[0.01]$} & {$[0.07]$} & {$[0.18]$} \\
\hline cpy & $\begin{array}{l}0.76 \\
(2.23)\end{array}$ & $\begin{array}{l}1.32 \\
(2.00)\end{array}$ & $\begin{array}{l}2.52 \\
(1.91)\end{array}$ & $\begin{array}{l}5.67 \\
(2.69)\end{array}$ & $\begin{array}{l}7.54 \\
(3.27)\end{array}$ & $\begin{array}{l}7.85 \\
(3.95)\end{array}$ & $\begin{array}{l}10.78 \\
(4.62)\end{array}$ \\
\hline cdy & $\begin{array}{l}-0.27 \\
(-1.10)\end{array}$ & $\begin{array}{l}-0.51 \\
(-1.11)\end{array}$ & $\begin{array}{l}-1.35 \\
(-1.48)\end{array}$ & $\begin{array}{l}-2.96 \\
(-1.92)\end{array}$ & $\begin{array}{l}-2.50 \\
(-1.76)\end{array}$ & $\begin{array}{l}-0.82 \\
(-0.55)\end{array}$ & $\begin{array}{l}0.66 \\
(0.38)\end{array}$ \\
\hline$\overline{R^{2}}$ & {$[0.01]$} & {$[0.03]$} & {$[0.05]$} & {$[0.17]$} & {$[0.27]$} & {$[0.32]$} & {$[0.47]$} \\
\hline
\end{tabular}


Table 7: Long-horizon regressions of returns on cpy, cay and 'usual suspects

$$
\sum_{l=1}^{k} r_{t+l}-r_{t+l}^{f}=\mathbf{z}_{t}^{\prime} \boldsymbol{\delta}_{k}+v_{k t}
$$

\begin{tabular}{cccccccc}
$\mathbf{z}_{t}$ & Horizon $k$ in quarters & & & & \\
\hline & 1 & 2 & 4 & 8 & 12 & 16 & 24
\end{tabular}

\begin{tabular}{lccccccc}
\hline \multicolumn{7}{c}{ Panel I: cpy and cay alone } \\
\hline cpy & 0.11 & 0.10 & -0.09 & 1.10 & $\mathbf{3 . 5 2}$ & $\mathbf{5 . 8 9}$ & $\mathbf{9 . 5 2}$ \\
& $(0.35)$ & $(0.18)$ & $(-0.10)$ & $(0.86)$ & $(2.28)$ & $(3.16)$ & $(4.05)$ \\
& & & & & & & \\
cay & $\mathbf{1 . 4 5}$ & $\mathbf{2 . 9 4}$ & $\mathbf{5 . 9 6}$ & $\mathbf{9 . 2 1}$ & $\mathbf{9 . 1 6}$ & 7.93 & $\mathbf{9 . 3 5}$ \\
& $(3.06)$ & $(3.44)$ & $(3.73)$ & $(4.81)$ & $(3.37)$ & $(1.87)$ & $(2.06)$ \\
& & & & & & & \\
$\overline{R^{2}}$ & {$[0.06]$} & {$[0.11]$} & {$[0.21]$} & {$[0.34]$} & {$[0.41]$} & {$[0.45]$} & {$[0.56]$}
\end{tabular}

Panel II: cpy, res and Usual Suspects

\begin{tabular}{|c|c|c|c|c|c|c|c|}
\hline \multicolumn{8}{|c|}{ Panel II: cpy, res and Usual Suspects } \\
\hline cpy & $\begin{array}{c}\mathbf{0 . 5 6} \\
(2.22)\end{array}$ & $\begin{array}{c}\mathbf{1 . 0 0} \\
(2.12)\end{array}$ & $\begin{array}{c}\mathbf{1 . 6 8} \\
(2.02)\end{array}$ & $\begin{array}{c}\mathbf{3 . 7 6} \\
(3.23)\end{array}$ & $\begin{array}{l}\mathbf{6 . 1 3} \\
(4.37)\end{array}$ & $\begin{array}{l}7.98 \\
(5.59)\end{array}$ & $\begin{array}{l}\mathbf{1 0 . 9 2} \\
(6.14)\end{array}$ \\
\hline res & $\begin{array}{c}\mathbf{1 . 4 4} \\
(2.87)\end{array}$ & $\begin{array}{l}\mathbf{2 . 9 2} \\
(3.23)\end{array}$ & $\begin{array}{l}\mathbf{5 . 9 2} \\
(3.65)\end{array}$ & $\begin{array}{l}\mathbf{8 . 9 6} \\
(3.83)\end{array}$ & $\begin{array}{l}\mathbf{8 . 8 9} \\
(2.58)\end{array}$ & $\begin{array}{l}7.96 \\
(1.82)\end{array}$ & $\begin{array}{l}\mathbf{1 1 . 1 1} \\
(2.53)\end{array}$ \\
\hline$d-p$ & $\begin{array}{l}0.002 \\
(0.14)\end{array}$ & $\begin{array}{l}0.003 \\
(0.11)\end{array}$ & $\begin{array}{l}-0.002 \\
(-0.03)\end{array}$ & $\begin{array}{l}-0.004 \\
(-0.04)\end{array}$ & $\begin{array}{l}0.01 \\
(0.06)\end{array}$ & $\begin{array}{l}0.01 \\
(0.05)\end{array}$ & $\begin{array}{l}0.21 \\
(1.22)\end{array}$ \\
\hline$d-e$ & $\begin{array}{c}-0.006 \\
(-0.19)\end{array}$ & $\begin{array}{l}-0.009 \\
(-0.16)\end{array}$ & $\begin{array}{l}0.02 \\
(0.17)\end{array}$ & $\begin{array}{l}0.08 \\
(0.47)\end{array}$ & $\begin{array}{l}0.11 \\
(0.46)\end{array}$ & $\begin{array}{l}0.17 \\
(0.75)\end{array}$ & $\begin{array}{l}\mathbf{0 . 5 5} \\
(2.37)\end{array}$ \\
\hline$T-b i l l$ & $\begin{array}{l}-0.02 \\
(-1.19)\end{array}$ & $\begin{array}{l}-0.04 \\
(-1.14)\end{array}$ & $\begin{array}{l}-0.02 \\
(-0.36)\end{array}$ & $\begin{array}{l}0.10 \\
(1.57)\end{array}$ & $\begin{array}{l}0.08 \\
(1.09)\end{array}$ & $\begin{array}{l}0.04 \\
(0.50)\end{array}$ & $\begin{array}{l}0.10 \\
(0.99)\end{array}$ \\
\hline & {$[0.06]$} & {$[0.11]$} & {$[0.20]$} & {$[0.35]$} & {$[0.41]$} & {$[0.45]$} & {$[0.61]$} \\
\hline
\end{tabular}

NOTES: res is the resiudeal of a regression of $c a y$ on $c p y$. $d-p$ and $d-e$ denote the dividend-price and teh dividend-earnings ratio respectively and T-bill is the cyclical component of the three months treasury-bill rate obtained through an HP-filetr with $\lambda=1600$. For further notes seee previous tables. 
Table 8: Determinants of the declining correlation between cay and cpy

Regressions of the form $C O R R_{t}=\boldsymbol{\theta}^{\prime} \mathbf{z}_{t}+v_{t}$

\begin{tabular}{|c|c|c|c|c|}
\hline \multirow[t]{2}{*}{$\mathbf{z}_{t}$} & \multicolumn{4}{|c|}{ Estimates of $\boldsymbol{\theta}$ (dep. variable always $C O R R_{t}$ ) } \\
\hline & $(1)$ & $(2)$ & $(3)$ & $(4)$ \\
\hline full banking deregulation & $\begin{array}{l}-0.016 \\
(-3.27)\end{array}$ & - & $\begin{array}{l}-0.05 \\
(-6.03)\end{array}$ & $\begin{array}{c}-0.176 \\
(-16.53)\end{array}$ \\
\hline stock market participation & - & $\begin{array}{c}-0.04 \\
(-2.28)\end{array}$ & $\begin{array}{c}0.17 \\
(4.63)\end{array}$ & $\begin{array}{l}-0.738 \\
(-8.16)\end{array}$ \\
\hline interaction term & - & - & - & $\begin{array}{c}0.0080 \\
(10.82)\end{array}$ \\
\hline constant & $\begin{array}{c}1.94 \\
(14.77)\end{array}$ & $\begin{array}{c}2.56 \\
(4.96)\end{array}$ & $\begin{array}{c}-1.19 \\
(-1.69)\end{array}$ & $\begin{array}{l}16.10 \\
(9.26)\end{array}$ \\
\hline$\overline{R^{2}}$ & 0.46 & 0.19 & 0.80 & 0.91 \\
\hline
\end{tabular}




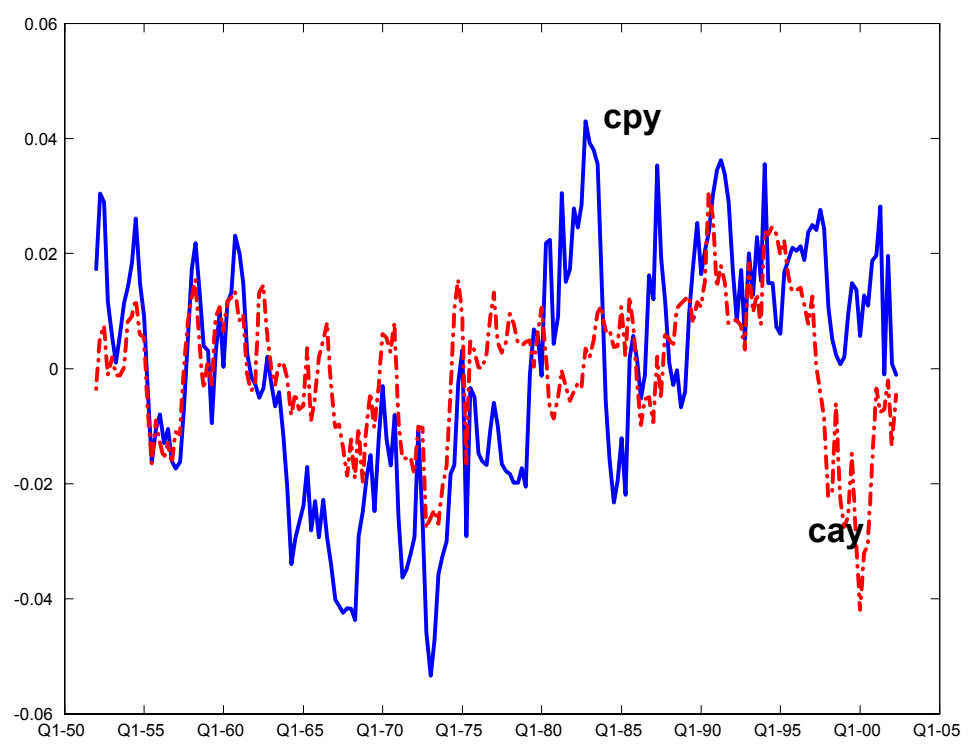

Figure 1: $c p y=c-0.27 p-0.81$ versus Lettau-Ludvigson (2004) cay.

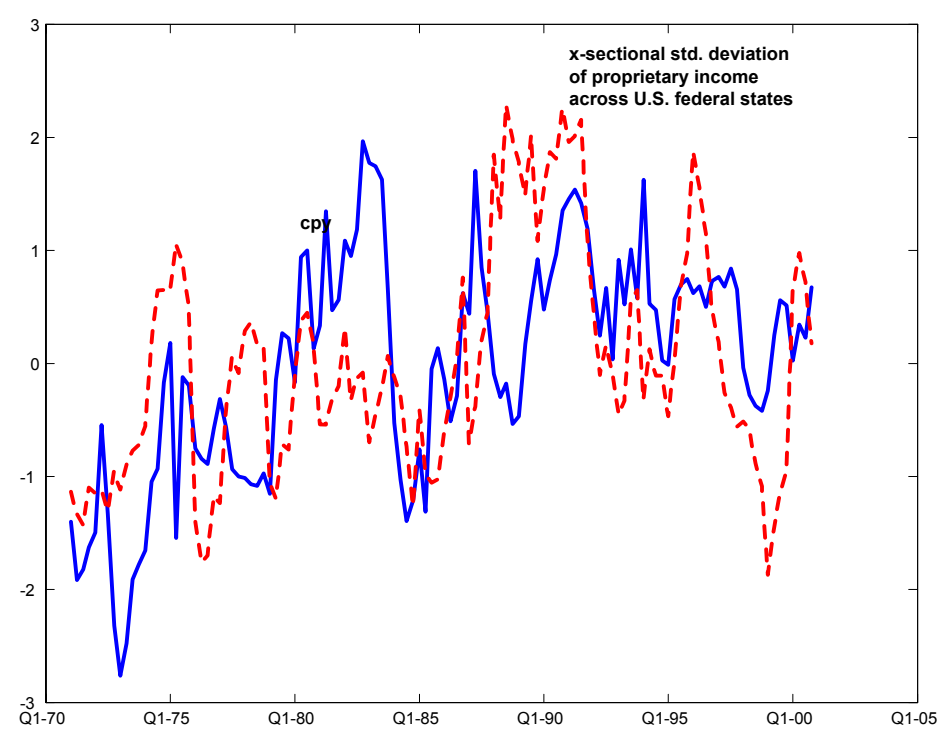

Figure 2: cpy (1969-2002) vs. the cross-sectional variance of growth rates in proprietary income across U.S. federal states. 

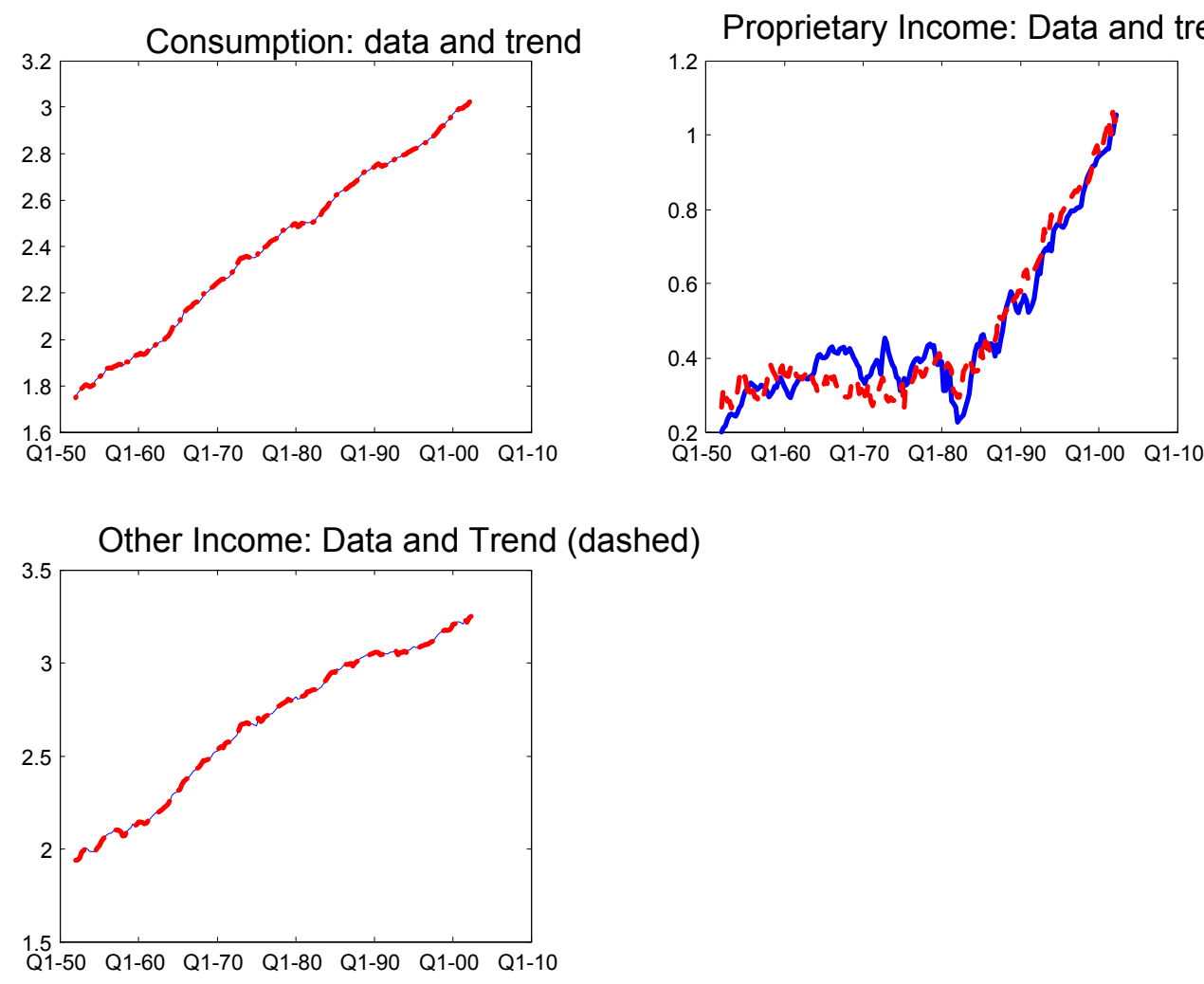

Figure 3: (Logarithmic) Data (solid line) vs their trend components (dashed) as identfied from the VECM. 


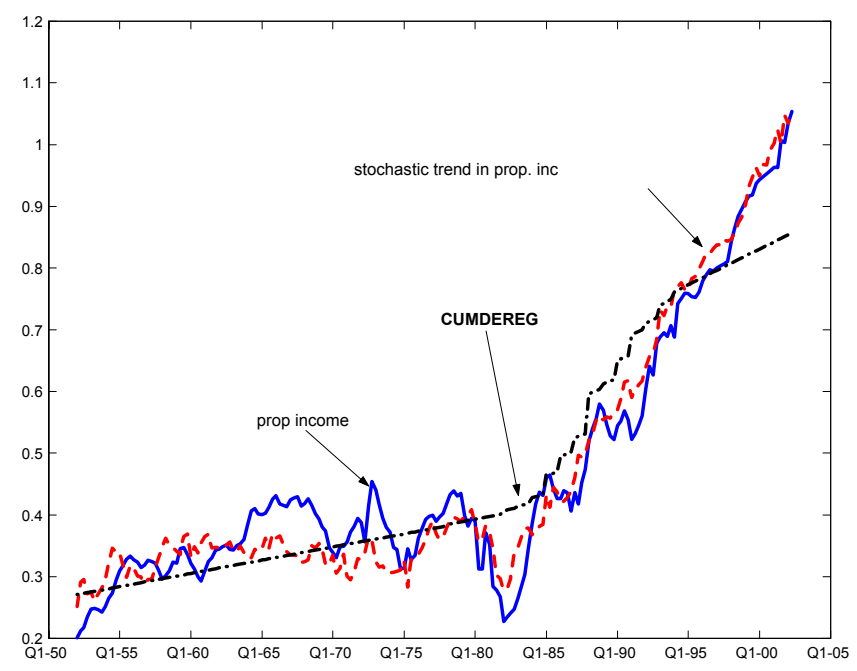

Figure 4: The figures plots proprietary income, the stochastic trend identified from the VECM and the fitted value of the regression of $p$ on the banking derfulation trend $C U M D E R E G$.

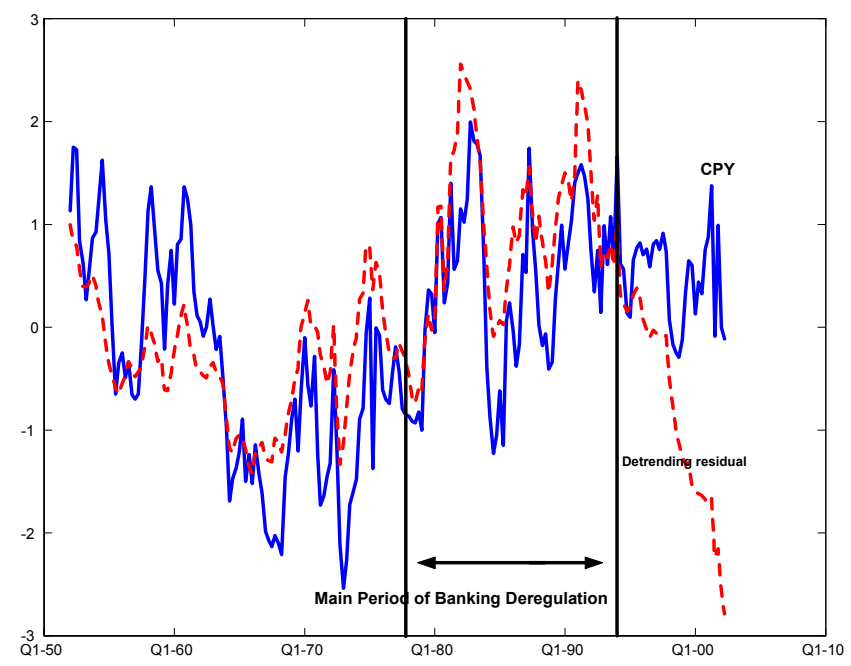

Figure 5: cpy versus the residual of the regression on $p$ on the banking deregulation trend $C U M D E R E G$. 


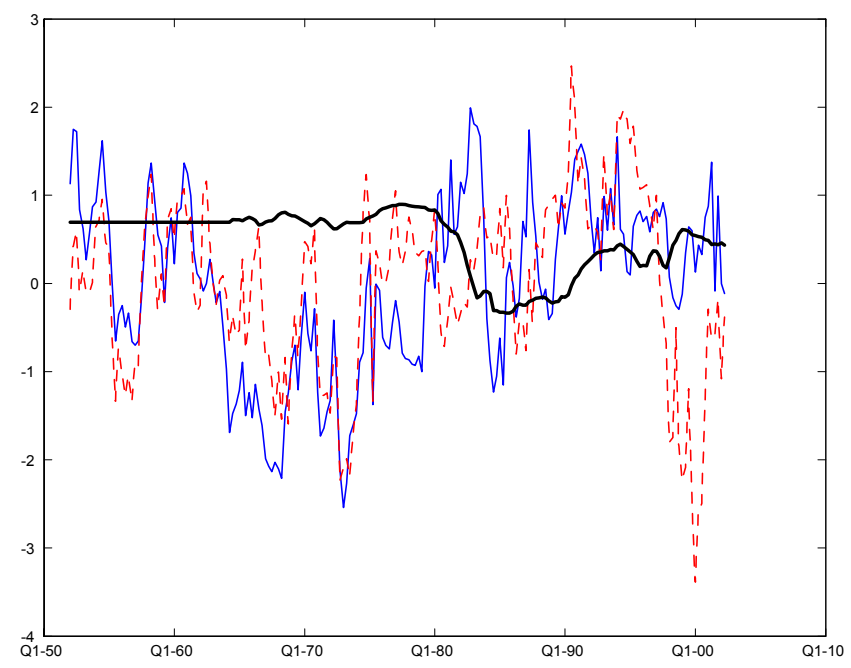

Figure 6: Rollling window correlation $C O R R_{t}=\operatorname{corr}\left(\operatorname{cay}_{t-20: t}, c p y_{t-20: t}\right)$ (solid line). Thin lines reproduce cay and cpy respectively.

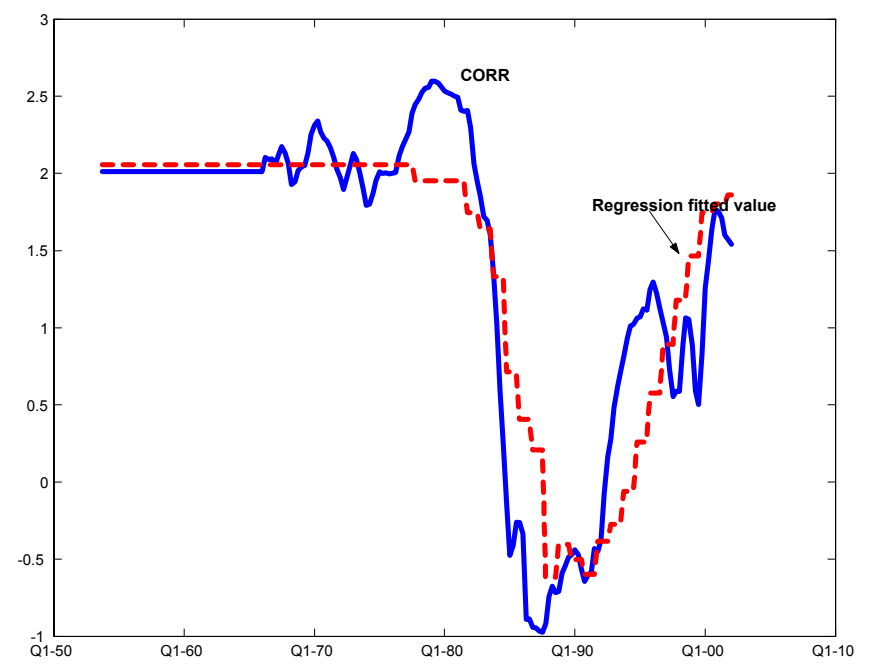

Figure 7: Rolling-window correlation $C O R R$ (solid line) and the fitted value of the regression of $C O R R$ on the banking deregulation and stock market participation measures (for regresssion details see table 8 ) 